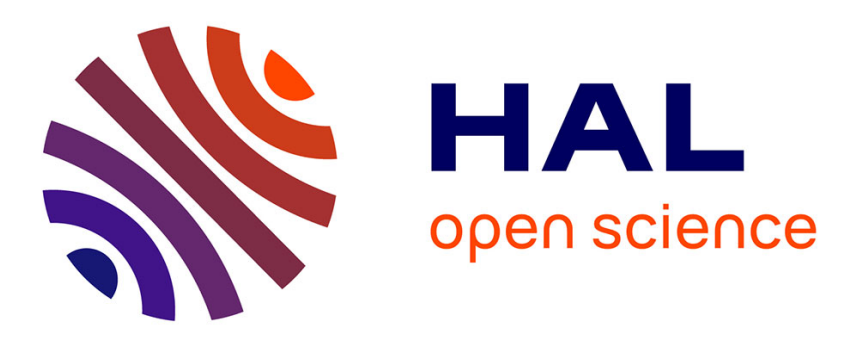

\title{
HRTEM study of defects in twin boundaries of ultra fine grained copper
}

Mohamed Sennour, Sylvie Lartigue-Korinek, Yannick Champion, Martin

Hÿtch

\section{> To cite this version:}

Mohamed Sennour, Sylvie Lartigue-Korinek, Yannick Champion, Martin Hÿtch. HRTEM study of defects in twin boundaries of ultra fine grained copper. Philosophical Magazine, 2007, 87 (10), pp.14651486. 10.1080/14786430601021611 . hal-00513787

\section{HAL Id: hal-00513787 \\ https://hal.science/hal-00513787}

Submitted on 1 Sep 2010

HAL is a multi-disciplinary open access archive for the deposit and dissemination of scientific research documents, whether they are published or not. The documents may come from teaching and research institutions in France or abroad, or from public or private research centers.
L'archive ouverte pluridisciplinaire HAL, est destinée au dépôt et à la diffusion de documents scientifiques de niveau recherche, publiés ou non, émanant des établissements d'enseignement et de recherche français ou étrangers, des laboratoires publics ou privés. 


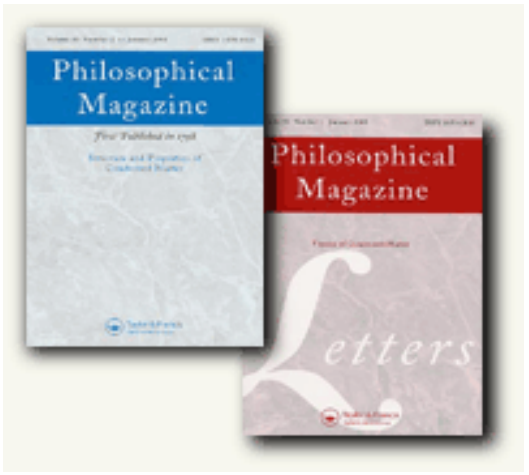

\section{HRTEM study of defects in twin boundaries of ultra fine grained copper}

\begin{tabular}{|c|c|}
\hline Journal: & Philosophical Magazine \& Philosophical Magazine Letters \\
\hline Manuscript ID: & TPHM-05-Sep-0405.R2 \\
\hline Journal Selection: & Philosophical Magazine \\
\hline $\begin{array}{l}\text { Date Submitted by the } \\
\text { Author: }\end{array}$ & 13-Sep-2006 \\
\hline Complete List of Authors: & $\begin{array}{l}\text { Sennour, Mohamed; Centre d'Etudes de Chimie Métallurgique, UPR } \\
2801 \text { CNRS, F-94407 Vitry sur Seine, France } \\
\text { Lartigue-Korinek, Sylvie; Centre d'Etudes de Chimie Métallurgique, } \\
\text { UPR } 2801 \text { CNRS, F-94407 Vitry sur Seine, France } \\
\text { Champion, Yannick; Centre d'Etudes de Chimie Métallurgique, UPR } \\
2801 \text { CNRS, F-94407 Vitry sur Seine, France } \\
\text { HYTCH, Martin; Centre d'Etudes de Chimie Métallurgique, UPR } 2801 \\
\text { CNRS, F-94407 Vitry sur Seine, France }\end{array}$ \\
\hline Keywords: & $\begin{array}{l}\text { copper, dislocations, grain boundaries, HRTEM, ultrafine-grained } \\
\text { materials }\end{array}$ \\
\hline Keywords (user supplied): & Geometric Phase Analysis \\
\hline
\end{tabular}

\section{S) ScholaroNE \\ Manuscript Central}




\section{HRTEM study of defects in twin boundaries of ultra fine grained copper}

M. SENNOUR, S. LARTIGUE-KORINEK*, Y. CHAMPION and M. J. HŸTCH**

Centre d'Etudes de Chimie Métallurgique, UPR 2801 CNRS, F-94407 Vitry sur Seine, France

*Corresponding author. Email: lartigue@glvt-cnrs.fr

**currently: CEMES-CNRS, 28 rue Jeanne Marvig, 31055 Toulouse, France 


\begin{abstract}
Twin boundaries (TBs) in ultra-fine grained (UFG) copper prepared by powder metallurgy are investigated using high-resolution transmission electron microscopy (HRTEM) and Geometric Phase Analysis (GPA). Specimens before and after mechanical deformation (compression of 40\%) are analysed and emphasis has been made on study of TBs defects. Twin boundaries in the as-processed specimens are in majority disoriented from the perfect $\Sigma 3$ coincidence. They present a faceted structure with coherent $\{111\}$ and incoherent $\{112\}$ facets. The latter have a 9R structure and the $\{111\} /\{112\}$ junctions are associated with sessile dislocations of Frank type $\left(\mathbf{b}=\frac{a}{3}<111>\right)$. Shockley glissile dislocations with Burgers vector of type $\mathbf{b}=\frac{a}{6}<112>$ are also present. This microstructure is interpreted in terms of the absorption and decomposition at room temperature of lattice dislocations ( $60^{\circ}$ type). After mechanical deformation, an enrichment of twins in dislocations and a decrease of step density and height is observed and quantified by statistical analysis. Deformation mechanisms of UFG copper are discussed in the light of these observations.
\end{abstract}

Keywords: Ultrafine-grained materials, Copper, Dislocations, Grain boundaries, HRTEM, Geometric phase analysis. 


\section{Introduction}

Ultra-fine grained (UFG) materials with grain sizes in the range of 50-500 nm exhibit unique mechanical properties [1]. The high volume fraction of grain boundaries in these materials modifies the usual mechanisms of deformation by interfering with the generation and movement of dislocations and by promoting grain boundary sliding (GBS) [2-4].

Before the micro-mechanisms involved in deformation can be understood, a detailed knowledge of the structure of the grain boundaries $(\mathrm{GBs})$ is required. High-resolution transmission electron microscopy (HRTEM) is a powerful tool for the study of grain boundary structure at the nanometre scale. Combined with geometric phase analysis (GPA) [5], quantitative information can be obtained concerning local strains, lattice rotations, and variations in lattice parameter.

GB structure in nanocrystalline copper and the interaction with lattice dislocations has received some attention in order to explain the unique properties of these materials, particularly high strengthening. In severe plastic deformed (SPD) copper [6-8], the microstructure is complex and GBs are heavily strained and mostly in non-equilibrium states due to extrinsic dislocations. These characteristics have made nanoscale investigation of the GB structure in these materials difficult. Observations have then been limited to small-angle grain boundaries and deformation twins.

In electro-deposited nanostructured $\mathrm{Cu}$ [9-11], the microstructure is characterised by the presence of nano-sized twins, the density of which may be changed by modifying the electro-deposition parameters. It has been established that twin boundaries (TBs) act as strong barriers to dislocations motion, like conventional GBs, and consequently they are considered to play a predominant role in the deformation mechanism. In the as-deposited material, TBs are perfectly coherent and atomically sharp; after deformation, TBs present a high density of defects with the formation of steps and jogs. Intergranular dislocations have been mostly 
identified as Shockley partials left by matrix dislocations crossing the boundaries during deformation.

In the present work nanocrystalline copper is obtained by powder metallurgy and like other UFG copper materials it has been shown to combine ultrahigh strength and ductility displaying near-perfect elastoplastic behaviour [12]. TEM investigations carried out on asprocessed specimens reveal a microstructure combining features from both SPD and electrodeposited materials i.e. a noticeable activity of dislocations and a marked presence of twins [13].

From a deformation behaviour point of view, coherent TBs form a rather rigid element of the microstructure. Dislocation accommodation mechanisms are more difficult in TBs than in other GBs due to their low energy and low intergranular diffusivity $[14,15]$. Thus material properties must be affected if coherent TBs are a substantial part of the microstructure. Moreover, it is interesting to analyse carefully these boundaries as they hold a «memory » of GB phenomena that have occurred during deformation but which could disappear in general GBs due to dislocation accommodation processes [16]. Besides, HRTEM investigations of TBs are facilitated due to the presence of a common $<110>$ zone axis. They may provide a better comprehension of the dislocation activity and consequently of deformation mechanisms.

This work presents HRTEM investigations of the TB structure at a nanometre scale and their interaction with lattice dislocations in UFG copper, with the aim to improve understanding of deformation micromechanisms of ultra-fine grained copper. The materials preparation is presented in the next Section. GB defects are characterised by two techniques: classical Burgers circuit mapped to the $\Sigma 3$ DSC lattice [17], and geometrical phase analysis detailed in Section 3. The latter has been used previously for the analysis of dislocations [18] and low-angle grain boundaries [19] and is adapted for the study of twin boundary 
dislocations. It permits a rapid visualisation of dislocations at the mesoscopic microstructural scale provided that the discontinuity characteristics in the GPA images are unambiguously interpreted. This is achieved by a careful comparison between the two techniques.

Results are presented for the as-processed material (Section 4), and after mechanical deformation of $40 \%$ in compression (Section 5). The modifications in twin structure are related to the deformation mechanisms.

\section{Experimental procedure}

Bulk UFG copper specimens are produced through powder metallurgy processing of nanocrystalline powders [13]. Powders are synthesized by overheating a molten copper droplet and evaporation-condensation in a cryogenic liquid (nitrogen in our case) [20]. The process consists of low temperature sintering of pre-compacts in a reducing $\mathrm{H}_{2}$ atmosphere to eliminate the oxide layer, whilst avoiding grain growth. Materials with $10 \%$ residual porosity are then processed by differential extrusion to obtain full densification (>99\%).

Thin foils are obtained by cutting copper cylinders parallel to the extrusion direction. The obtained platelets with $1 \mathrm{~mm}$ of thickness are mechanically polished to $0.1 \mu \mathrm{m}$ of thickness. Then, disks of $3 \mathrm{~mm}$ diameter are extracted and electrochemically thinned with an apparatus (TENUPOL 5 - Struers) using a commercial solution (D2 - Struers) at $-15^{\circ} \mathrm{C}$ in order to limit oxidation of the samples. Practical difficulties with HRTEM studies of nanocrystalline material include sample orientation, grain superposition and surface oxidation.

Axial cutting favours $<110>$ texture. This is important in the case of copper (FCC metal) since only $\{111\}$ planes, $0.2088 \mathrm{~nm}$ spacing, can be imaged by the TOPCON 002B microscope $(200 \mathrm{kV}$, Cs:0.4 mm, resolution: $0.185 \mathrm{~nm})$. Images are acquired on both Imaging Plates (Fuji, Raytest France) and negatives, with image analysis carried out using in-house routines written for Digital Micrograph 3.5 (Gatan). Images distortions due to the microscope aberrations, notably those due to the projector lenses, have been calibrated on silicon single 
crystal and eliminated from the HREM images before analysis [21]. Furthermore, all but the first image presented in the paper have been Fourier filtered to eliminate noise. The masks used in Fourier space for this filtering are of the same size as that used in the geometric phase analysis.

\section{Geometric Phase Analysis}

Geometric phase analysis is an image-processing routine that is sensitive to small displacements of the lattice fringes in HRTEM images [5]. Displacements can be measured relative to a fixed reference lattice directly from high-resolution images by calculating the local Fourier components of the lattice fringes. A mask is applied in the Fourier transform of the image, centred around the periodicity of interest, and the inverse-Fourier transform performed. The resulting phase of the local Fourier components is related to the displacement field $\mathbf{u}(\mathbf{r})$ by the following expression:

$$
P_{g}(\mathbf{r})=-2 \pi \mathbf{g} \cdot \mathbf{u}(\mathbf{r})
$$

where $g$ is the reciprocal lattice vector corresponding to the lattice fringes analysed. To determine the two-dimensional displacement field, two phase images $P_{g 1}(\boldsymbol{r})$ and $P_{g_{2}}(\boldsymbol{r})$ are required:

$$
\mathrm{u}(r)=\frac{1}{2 \pi}\left[\mathrm{P}_{\mathrm{g}_{1}}(r) a_{1}+\mathrm{P}_{\mathrm{g}_{2}}(r) a_{2}\right]
$$

where $\boldsymbol{a}_{1}$ and $\boldsymbol{a}_{2}$ are the basis vectors for the lattice in real space corresponding to the reciprocal lattice defined by $\boldsymbol{g}_{1}$ and $\boldsymbol{g}_{2}$ [6]. Having calculated the displacement field, the full deformation tensor follows automatically by numerical differentiation :

$$
\begin{aligned}
& \boldsymbol{\varepsilon}_{\mathbf{i j}}=\frac{1}{2}\left(\frac{\partial u_{i}}{\partial x_{j}}+\frac{\partial u_{j}}{\partial x_{i}}\right) \\
& \boldsymbol{\omega}_{\mathbf{i j}}=\frac{1}{2}\left(\frac{\partial u_{j}}{\partial x_{i}}-\frac{\partial u_{i}}{\partial x_{j}}\right)
\end{aligned}
$$


where $\varepsilon_{\mathrm{ij}}$ are the expansion/contraction and shear components of the strain, and $\omega_{\mathrm{ij}}$ is the rigid-body rotation (anticlockwise positive). Small distortions are assumed.

In this paper, we develop a new aspect of GPA for the analysis of lattice planes across grain boundaries. For lattice fringes common to both grains, local variations of the reciprocal lattice vector can be determined in the usual way by numerically differentiating the phase:

$$
\boldsymbol{g}(\boldsymbol{r})=\boldsymbol{g}+\frac{1}{2 \pi} \nabla P_{g}(\boldsymbol{r})
$$

from which the local orientation, spacing, and hence deformation of the fringes can be calculated directly [5]. In such cases the Fourier filtering uses a single mask centred on the common reciprocal lattice vector. However, lattice planes usually change in orientation by large amounts across grain boundaries and cannot be included in a single mask. We have therefore devised a method where two masks are used during the Fourier filtering. Filter masks are placed simultaneously around $\boldsymbol{g}^{1}$ (of grain 1) and $\boldsymbol{g}^{2}$ (of grain 2) and the reference lattice chosen as the average of $\boldsymbol{g}^{1}$ and $\boldsymbol{g}^{2}$. The local lattice vector is then calculated as before from Equation (4).

\section{As-processed material}

\subsection{Overall morphology and structure of twin boundaries}

\subsubsection{TEM observations}

Figure 1a shows a low magnification TEM micrograph obtained on the as-processed specimen. Ultrafine grains are mainly of equiaxe shape with sizes ranging between several tens of nanometres to hundreds of nanometres. Grains are not heavily strained though some dislocation tangles, generally localized in one extremity of grains, are observed. However, an important fraction of grains are divided into parallel bands of twins with average width of 60 $\mathrm{nm}$ (see figure 1b). Dislocation debris are localized on and between TBs. Consequently, the latter present a small deviation angle $\Delta \theta$ to perfect $\Sigma 3\{111\}$ coincidence. Magnification of 
the image reveals that TBs have a particular faceted structure with big coherent $\{111\}$ and short incoherent $\{112\}$ micro-facets (see figure 1c). It is also interesting to note on the enlargement of a step (see figure 1d) that the incoherent facet exhibit moiré fringes and is not exactly at $90^{\circ}$ to the coherent facet as might be expected but is slightly inclined.

[Insert figures 1a-d about here].

\subsubsection{Geometric Phase Analysis}

GPA provides a direct and easy visualization of the overall GB content of dislocations having edge components. Figure 2 a shows a HRTEM image of a faceted near- $\Sigma 3$ boundary $\left(\Delta \theta=2.7^{\circ}\right)$ and the corresponding geometric phase image $P_{\{111\}}$ for the common lattice planes (see figure $2 b)$. The phase image was calculated from the set of $(11 \overline{1})_{1} /(111)_{2}$ lattice fringes (where indices 1 and 2 denote each grain) parallel to the twin boundary plane taking crystal 1 (C1) as the reference lattice. Discontinuities in the phase correspond to dislocation core positions [18]. Pseudo-periodic arrays of dislocations can be observed along boundaries, similarly to the analysis of low-angle grain boundaries with GPA [19].

[Insert figures $2 \mathrm{a}-\mathrm{b}$ about here]

Based on the simplified Read-Shockley formula [22], the theoretical dislocations spacing can be calculated :

$$
d=\frac{\boldsymbol{b}_{\perp}}{2 \sin (\Delta \theta / 2)} \cong \frac{\boldsymbol{b}_{\perp}}{\Delta \theta}
$$

where $\Delta \theta$ is the deviation from the perfect $\Sigma 3$ coincidence $\left(2.7^{\circ}\right.$ in the present case) and $\boldsymbol{b}_{\perp}$ is the component of the Burgers vector perpendicular to the boundary plane, in this case identified as $\mathbf{b}=\frac{a}{3}[\overline{1} \overline{1} 1]_{1}=\frac{a}{3}[\overline{1} \overline{1} \overline{1}]_{2}$ (Frank type dislocation) (see Paragraph 4.2.1). The theoretical value of $3.7 \mathrm{~nm}$ agrees very well with the experimental value of $3.75 \mathrm{~nm}$. 
Therefore, the deviation $\Delta \theta$ is mainly accommodated by the arrangement of Frank sessile dislocations.

Lattice rotation and deformation maps derived from the phase image via Equation (4) are shown in figures $3 \mathrm{a}$ and $\mathrm{b}$ respectively. Only the rotation $\omega$ of the common $(11 \overline{1})_{1}=(111)_{2}$ planes and one component of the deformation tensor are presented. For this image, the phase from the other lattice planes was too noisy to determine the full 2dimensional displacement field and strain. The fact that the contours are not smooth lines, but tend to meander locally, is due to the noise present in the image. The contours show that deformation is localized principally around dislocations cores while between dislocations orientation varies smoothly from one grain to the other across the boundary. Furthermore, no long-range strain fields are observed which is consistent with the fact that the deformation is completely accommodated by the quasi-periodic array of Frank sessile dislocations.

Based on isotropic elastic theory, a simplified local rigid-body rotation expression is obtained [19]:

$$
\boldsymbol{\omega}(\boldsymbol{r})=\frac{\boldsymbol{b} \cdot \boldsymbol{r}}{2 \pi r^{2}}
$$

This relation is interesting since it provides information on the direction of $\boldsymbol{b}$ by analysing the orientation of the lobe's maxima, where $\boldsymbol{b}$ is parallel to $\boldsymbol{r}$. The majority of lobes are parallel to $[11 \overline{1}] 1$ and $[111]_{2}$ respectively, which is in agreement with Burgers vectors (BVs) of the type $\mathbf{b}=\frac{a}{3}[\overline{1} \overline{1} 1]_{1}=\frac{a}{3}[\overline{1} \overline{1} \overline{1}]_{2}$. Some lobes present different orientations (see arrow) which may be attributed to dislocations with different BVs type. This is a qualitative method to predict directly dislocation BVs at a microscopic scale. It is validated by detailed circuit analyses that will appear in the next Section (see Paragraph 4.2.1). Nevertheless it is worth noting that despite the noise and the presence of moiré fringes in the image due to copper 
oxide on the specimen surface, useful information can be obtained particularly concerning the dislocations organisation and the BVs distribution.

[Insert figures 3a-d about here].

Experimental results are compared with theoretical strain and rotation maps obtained by applying the same procedure to the displacement fields calculated from isotropic elastic theory (see figures $3 \mathrm{c}$ and d). The simulation is carried out taking into account only Frank dislocations. The form of the strain and the rotation fields are quite well reproduced. This good agreement supports the reliability of BVs prediction from phase analysis and the sufficiency of isotropic elastic theory for our uses.

\subsection{Local atomic structure of TBs and configuration of intergranular dislocations}

This Section details the atomic structure of coherent and incoherent twins by examining first the junction between the two facets. The various types of the observed intergranular dislocations are also described.

\subsection{1. $\{111\} /\{112\}$ junction}

Figure 4 shows an HRTEM image obtained along the [1 $\overline{1} 0]$ zone axis and where atomic columns are white. A careful inspection of the image highlights the presence of a dislocation at the junction of the $\{111\}$ and $\{112\}$ facets. These dislocations have been analysed using the circuit mapping method for grain-boundaries [17]. In each crystal, a circuit including several coincidence site lattice (CSL) units is drawn above and below the defects and the vectors $S_{1}$ and $S_{2}$ joining two equivalent sites in each crystal are measured (see figure 4). The Burgers vector is then given by the relation:

$$
\mathbf{b}=S_{1}-S_{2}
$$

Dislocations are then identified as Frank dislocations with BVs $\mathbf{b}=\frac{a}{3}[\overline{1} \overline{1} 1]_{1}=\frac{a}{3}[\overline{1} \overline{1} \overline{1}]_{2}$, which is in agreement with GPA predictions. Such a junction configuration differs from that 
which has been observed in other metals, like aluminium [23] where no dislocation has been observed, and in gold [24] where a dislocation with Burgers vector $\sim \frac{\mathrm{a}}{9}<111>$ was suggested. In that case, a dislocation is not necessarily present at the junction, where only strong strain fields may be observed [25]. Moreover, in our case, the Frank dislocations are associated with steps of different height, ranging from 3 to 15 atomic planes along the normal to the coherent twin orientation.

[Insert figure 4 about here].

\subsubsection{Coherent $\{111\}$ facets}

The coherent (111) facet presents different atomic structures. In figure 5, the structure of a $\{111\}$ boundary segment cannot be entirely described by a geometric model based on the coincidence site lattice. Local changes of the TB structure are observed that cannot be attributed to contrasts variations between the top and the bottom of the image as deduced from perfect twin image simulation.

Near the $\{111\} /\{112\}$ junctions (see white arrow), the boundary plane is no longer a plane of symmetry. Such a structure has been already observed in aluminium [23] and gold [24]. In aluminium, it is suggested that a local distortion accommodates the mismatch resulting from the fact that the two segments do not meet at a coincidence site. Faulted regions are equally observed (outlined zone). The total Burgers vector around the defect is equal to $\mathbf{b}^{*}=\frac{a}{6}[\overline{1} \overline{1} \overline{2}]_{1}=\frac{a}{6}[11 \overline{2}]_{2}$. A dissociation of a Shockley glissile dislocation into two products could produce such a stacking fault delimited by two partials of the type $\frac{a}{12}[\overline{1} \overline{1} \overline{2}]_{1}=\frac{a}{12}[11 \overline{2}]_{2}$. TB contains also several nano-steps associated to Shockley DSC dislocation with $\mathbf{b}^{* *}=\frac{a}{12}[\overline{1} \overline{1} \overline{2}]_{1}=\frac{a}{12}[11 \overline{2}]_{2}$ (projection of $\frac{a}{6}[1 \overline{2} \overline{1}]_{1}$ and $\left.\frac{a}{6}[2 \overline{1} \overline{1}]_{2}\right)$ 
These BVs lie in the boundary plane which explains the fact that they are not visible in $(11 \overline{1})_{1} /(111)_{2}$ geometric phase images as $\boldsymbol{g} \cdot \boldsymbol{b}=0$.

[Insert figure 5 about here].

\subsubsection{Incoherent $\{112\}$ facet}

Figure 6a shows a HRTEM image of a $\{112\}$ segment. The localization of the boundary plane in this case is not straightforward since the boundary is relaxed and no mirror symmetry plane can be directly positioned as in the case of the non relaxed $\Sigma 3\{112\}$ structure $[23,25]$. In order to determine the boundary structure, atoms belonging to successive $(2 \overline{2} 0)$ planes were coloured differently (see figure $6 \mathrm{~b}$ ). The resulting grain boundary presents a 9R structure already observed and calculated in gold [26], silver [27,28] and copper [29-32]. It consists in a thin layer ( $0.6 \mathrm{~nm}$ of thickness $)$ of close-packed stacking of f.c.c $\{111\}$ planes with an intrinsic stacking fault inserted every three planes. This layer is bounded by a small angle boundary and a large angle boundary. The small-angle boundary consists of Shockley partial dislocations, and the large-angle boundary is characterized by kite-shaped structural units [27-32]. The inclination of the $\{112\}$ facet obeys geometric and energetic considerations [29]. This structure implies a translation of (111) planes across the (112) interface. It is worth noting that the translation is not observed except in the close vicinity of the dislocation core. The absence of translation may originate from the constraint exercised by the neighbouring coherent twins [23].

[Insert figures 6a and $\mathrm{b}$ about here]

An attempt to give an accurate interpretation of atomic column positions from HRTEM images is, however, not relevant at this scale and so close to defects. Objective lens aberrations, dynamical scattering and Fourier filtering of the image will all introduce artifacts and local displacements of lattice fringes. In addition, the steps may be faceted in the viewing direction resulting in the superposition of structures. The analysis presented here is therefore 
indicative of the general morphological tendencies and not necessarily representative of the precise position of individual facets and steps within these facets. On the other hand, measurements of BVs remain reliable as circuits are mapped sufficiently far from defect cores.

\subsubsection{Boundary dislocations configurations}

Beside Frank and Shockley dislocations, other GB dislocation configurations are worth reporting as they are related to the incorporation and decomposition processes of lattice dislocations in boundaries.

Figure 7 shows an HRTEM image of a lattice dislocation in close proximity of a twin boundary. The dislocation line is parallel to $[1 \overline{1} 0]$ and the projected $\mathrm{BV}$ is $\mathbf{b}=\frac{a}{4}[\overline{1} \overline{1} 2]_{1}$. The dislocation most probably corresponds to a $60^{\circ}$ dislocation, characteristic of FCC metals, with total BV equal to $\frac{a}{2}[\overline{1} 01]_{1}$ or $\frac{a}{2}[0 \overline{1} 1]_{1}$. In copper, where the stacking fault energy is low $\left(40 \mathrm{~mJ} / \mathrm{m}^{2}\right), 60^{\circ}$ lattice dislocations generally dissociate to minimize the elastic energy into two Shockley partials, $30^{\circ}$ and $90^{\circ}$ with BVs of the type $\mathbf{b}=\frac{a}{6}<112>$ separated by a ribbon of a stacking fault. The dissociation width is estimated to range between 2.7 and 4.7 nm in copper [33]. In the present case, the two partials are too close to clearly observe the dissociation. In fact, it has been shown by atomistic simulation that the dissociation distance decreases when approaching the boundary [34].

[Insert figure 7 about here].

Figure 8a shows another dislocation / boundary configuration with an extra $\{111\}$ plane, lying close to a twin boundary, associated to a one atomic plane step in the TB plane. Circuit analysis of the total defect gives a Burgers vector of the type: 
$\mathbf{b}=\frac{a}{3}[\overline{1} \overline{1} 1]_{1}=\frac{a}{3}[\overline{1} \overline{1} \overline{1}]_{2}$. In order to identify BVs associated to both defects three reactions can be considered:

$$
\begin{aligned}
& \frac{a}{6}[\overline{1} \overline{1} 2]_{1}^{L}+\frac{a}{6}[\overline{1} \overline{1} 0]_{1}^{B} \rightarrow \frac{a}{3}[\overline{1} \overline{1} 1]_{1}^{T} \\
& \frac{a}{2}[\overline{1} 01]_{1}^{L}+\frac{a}{6}[\overline{1} \overline{2} \overline{1}]_{1}^{B} \rightarrow \frac{a}{3}[\overline{1} \overline{1} 1]_{1}^{T} \\
& \frac{a}{2}[0 \overline{1} 1]_{1}^{L}+\frac{a}{6}[\overline{2} \overline{1} \overline{1}]_{1}^{B} \rightarrow \frac{a}{3}[\overline{1} \overline{1} 1]_{1}^{T}
\end{aligned}
$$

Reactions are written with respect to crystal 1 where symbols $L, B, T$ denote lattice, boundary and total defects respectively.

Reactions (8b) and (8c) are equivalent and symbolise the recombination between a perfect lattice dislocation and a boundary Shockley partial. Reaction $8 \mathrm{a}$ represents the interaction between a lattice Shockley partial and a boundary sessile dislocation (stair-rod). The phase images have been found to be useful in determining the operating reaction. On the phase image calculated using the common $\{111\}$ planes only the boundary defect is visible (discontinuity in the image) (see figure 8b) and the orientation of the rotation lobe is more in agreement with a BV of the type $\frac{a}{6}[\overline{1} \overline{1} 0]_{1} \quad$ (see figure $8 \mathrm{c}$ ). Concerning the lattice defect, if dislocation with $\mathrm{BV}$ of the type $\frac{a}{2}[\overline{1} 01]_{1}^{L}$ or $\frac{a}{2}[0 \overline{1} 1]_{1}^{L} \quad$ is present, this should give rise to discontinuities in phase images calculated from (002) planes according to visibility criteria. However, this is not the case here. Consequently, it seems that the reaction $8 \mathrm{a}$ is the most probable.

The presence of the stair-rod in the boundary can be explained by the decomposition process of the lattice dislocation when entering the boundary (see Section 7.2 for details). Such reactions have been also proposed in the case of the interaction of a dissociated lattice dislocation with a $\Sigma 3$ boundary in silicon [35]. 
[Insert figures 8a-c about here].

Circuit analysis of the boundary dislocation in figure 9 gives a Burgers vector of the type $\mathbf{b}=\frac{a}{2}[\overline{1} \overline{1} 0]_{1}=\frac{a}{6}[\overline{1} \overline{1} \overline{4}]_{2} \quad:$ a perfect lattice sessile dislocation, the "Lomer" dislocation. It could result from reactions between DSC dislocations such as :

$$
\begin{aligned}
& \frac{a}{6}[\overline{1} \overline{1} \overline{2}]_{1}^{D S C}+\frac{\mathrm{a}}{3}[\overline{1} \overline{1} 1]_{1}^{D S C} \rightarrow \frac{a}{2}[\overline{1} \overline{1} 0]_{1} \\
& \frac{a}{6}[1 \overline{1}]_{2}^{D S C}+\frac{a}{3}[\overline{1} \overline{1} \overline{1}]_{2}^{D S C} \rightarrow \frac{a}{6}[\overline{1} \overline{1} \overline{4}]_{2}
\end{aligned}
$$

[Insert figure 9 about here].

\section{Material after deformation}

After a mechanical deformation consisting in a $40 \%$ compression test, the most significant change in the general microstructure is an enrichment of the TBs in dislocations and the formation of deformation micro-twins (see figures 10a and b). The latter, also known as deformation twins to differentiate them from growth twins investigated in this work, are mainly observed in severe plastic deformed materials [36]. They generally occur in extreme conditions of deformation as high applied stress, high deformation rate and low temperature. Anyway the critical shear stress for twinning in pure copper is about 300MPa [37]. As the yield stress is close to $350 \mathrm{MPa}$ (strain rate $10^{-4} \mathrm{~s}^{-1}$ ), well oriented grains can undergo twinning deformation.

[Insert figures 10a and $\mathrm{b}$ about here]

HRTEM investigations reveal a significant decrease of step heights compared to the as-processed specimen (see figure 11). The associated dislocations have been identified using circuit mapping to be Frank type. No offset of the extra plane in the neighbouring grain is now observed

[Insert figure 11 about here]. 
Figure 12a shows a typical TB in the deformed material exhibiting a curved form. GPA highlights the high density of boundary dislocations and confirms their Frank type as the lobes are mainly oriented along $[11 \overline{1}]_{1} /[111]_{2}$ directions (see figure $12 b$ ). Other dislocation types are also present (see lobes indicated by arrows). They probably correspond to stair-rod and Lomer dislocations as was suggested above. Furthermore, long-range strain fields are not visible in the deformation map (see figure 12c). Indeed, the good agreement between the experimental and the calculated dislocation spacing (from the Read-Shockley formula), 2.35 $\mathrm{nm}$ and $2.39 \mathrm{~nm}$ respectively, indicates that the sessile dislocations have been able to reorganise themselves during the deformation in order to accommodate the deviation $(\Delta \theta=$ $5^{\circ}$ ) from the perfect twin orientation. This requires short-range diffusion along the interface and might be supplemented by pipe-diffusion.

[Insert figures $12 \mathrm{a}-\mathrm{c}$ about here].

\section{Statistical analysis of twin boundaries}

The boundary dislocation spacing (d) and step height (h) were measured from several TBs, before and after deformation. About one hundred dislocations were analysed. Results are shown in Table 1 where the mean value of each parameter $\left(d_{m}, h_{m}\right)$ and their corresponding standard deviation $(\sigma)$ are reported. The dislocation spacing decreases after deformation (diminution of $d_{m}$ ), and dislocations rearrange to form a quasi-regularly spaced array (diminution of $\sigma$ ). The decrease in step height (diminution of $h_{m}$ ) mentioned above is clearly characteristic of the twins structure after deformation. Most of the steps in the deformed specimens are of two or three interplanar spacing whilst the Frank boundary dislocation causes a step of only one interplanar spacing.

[Insert Table 1 about here] 


\section{Discussion}

\subsection{Twin boundary structure}

The accommodation of the deviation from the perfect $\Sigma 3$ orientation relation implies a rearrangement of the sessile Frank dislocations. However, it is known that the latter move only by climb, which is a temperature-activated mechanism. The greater the GB selfdiffusion, the greater the mobility of dislocations along the boundary. Diffusion experiments carried out on nanostructured metals obtained by severe plastic deformation showed that the GB diffusion is higher than in coarse-grained materials [38]. For our samples, measurements of the self-diffusion activation energy during sintering give a value two times lower (50 $\left.\mathrm{kJ}^{\mathrm{mol}}{ }^{-1}\right)$ than the self-diffusion energy in coarse-grained copper (100 kJ.mol $\left.{ }^{-1}\right)$ [39]. This means that diffusion is active at an absolute temperature which is two times lower. The diffusion in metals is significantly active at about $0.4 T_{m}$ with $T_{m}$ the melting temperature of the material. Dividing this temperature by two corresponds to the room temperature for copper $\left(T_{m}, \mathrm{Cu}=1350^{\circ} \mathrm{K}\right)$. This hypothesis needs to be confirmed by the determination of the activation energy of the deformation mechanism.

\subsection{Dislocations - twin boundary interactions}

Several articles have dealt with the grain boundaries accommodation processes: transmission of lattice dislocations into neighbouring crystals or absorption within grain boundaries, they have been reviewed in $[14,40]$. Transmission may proceed "directly" providing that three criteria are fulfilled [41-43], but it has been experimentally shown that violations of the empirical rules occur even in the most favourable case of $\sum 3[44,45]$. Moreover, if the transmission criteria may be "easily" applied to perfect lattice dislocation, in case of low stacking fault materials, the entrance into the GB of partial dislocations whose Burgers vectors do not necessarily belong to the DSC lattice implies complex processes 
[33,34,46-48]. In most cases, an "indirect" transmission operates, implying absorption of lattice dislocations from one crystal followed by reaction within the GB and emission of lattice dislocations in the other crystal. These micro mechanisms occur more or less rapidly and emission takes place close or not the absorption GB region. Observation of lattice dislocations on one side and on the other side of the GB does not permit to decide what is the operating process. Only the detailed knowledge of the reactions at and within the interface allows to discriminate in favour of the "direct" process against the "indirect" one. Finally, a "direct" dislocation transmission requires very high stresses [34,49] and operates rarely, in particular in low SFE metals as copper [50,51].

In most GBs displaying high diffusivity (thus easy dislocation climb), the decomposition processes are favoured. For a dissociated lattice dislocation entering a boundary, two absorption mechanisms can be considered: the first one implies the decomposition in GB dislocation products of each partial [47]; the second one requires recombination of the partial dislocations to form perfect lattice dislocation before decomposition into GB dislocations with DSC Burgers vectors [48]. In the case of the $\sum 3$ (111) grain boundary in copper, a recent study combining bright-field and weak-beam TEM techniques reveals that decomposition process occur [50,51]. Finally, the decomposition of a lattice dislocation within singular GBs appears as an antagonistic process to its transfer in the neighbouring crystal, as was observed for a symmetrical $\ 9$ tilt GB in silicon [52].

In the present study, the $60^{\circ}$ lattice dislocation glides towards the TB with a leading $30^{\circ}$ and a trailing $90^{\circ}$ Shockley partials :

$$
\underset{60^{\circ}}{\frac{a}{[\overline{1} 01]_{1}}} \rightarrow \frac{\frac{a}{6}[\overline{1} \overline{1} 2]_{1}}{30^{\circ}}+\frac{\frac{a}{6}[\overline{2} 11]_{1}}{90^{\circ}}
$$

The dissociation distance decreases when approaching the boundary as demonstrated by atomistic simulations in copper [34]. When entering the boundary, the leading partial 
decomposes into a DSC glissile dislocation which moves away from the impact point and a sessile dislocation (stair-rod):

$$
\frac{a}{6}[\overline{2} 11]_{1}^{30^{\circ}} \rightarrow \frac{a}{6}[\overline{1} \overline{1} 0]_{1}^{S R}+\frac{a}{6}[\overline{1} 21]_{1}^{D S C}
$$

The emission of the glissile dislocation decreases the repulsive force exerted on the trailing dislocation and favours its recombination with the stair-rod to form a Frank dislocation, as for reaction $8 \mathrm{a}$. When gliding in the boundary, the glissile dislocation can also recombine with a Frank type dislocation:

$$
\frac{a}{6}[\overline{1} 21]_{1}+\frac{a}{3}[\overline{1} \overline{1} 1]_{1} \rightarrow \frac{a}{2}[\overline{1} 01]_{1}
$$

which corresponds to a $60^{\circ}$ lattice dislocation (see Section 4.3). Grain boundaries act then as sources and sinks of dislocations.

It is interesting to note that the dislocation interactions with boundaries are similar to those that happen in coarse-grained materials. However, the originality in the case of the UFG copper is that the processes are active at ambient temperature.

\subsection{Microstructure evolution and deformation mechanism}

The general microstructures before and after deformation tests are surprisingly similar. Even after $40 \%$ compression, grain morphology remains largely unchanged and very few entanglements of dislocations are observed. In coarse-grained copper, large areas of the grain interiors would be masked by strain and dislocation contrast in TEM observations. Nevertheless, dislocation activity during deformation must have been intense, as witnessed by the significant enrichment of twin boundaries in dislocations, and their increasingly curved morphology. The accommodation processes involve an easy migration of the $\{112\}$ facets, which is possible requiring only a slight displacement of atomic positions [28]. This helps the movement of the (111) boundary and subsequent decrease in step length [27]. 
The accommodation of the deformation cannot, however, be explained by a classical dislocation activity. We propose rather a mechanism based on grain boundaries acting as sources [53] and sinks for dislocations, with little or no intragranular interaction between dislocations. Dislocations emerge from grain boundaries where triple junctions and steps are the principal sources (see figures $13 \mathrm{a}$ and b), cross the grain interior, and are incorporated in the opposite boundary followed by the decomposition in DSC products, to minimize the elastic energy. Such reactions will promote the boundary sliding, assuming that glissile dislocations can be accommodated at triple junctions.

Dislocation accommodation is effectively observed in twins and general GBs after deformation (see Figure $13 \mathrm{~b}$ and $\mathrm{c}$ ). The accommodation kinetics being generally slower in singular GBs than in general GBs [54], this means that diffusion processes are even more effective in the other GBs of the microstructure. Indeed, the GB dislocation relaxation kinetics that have been proposed until now are all inversely proportional to the GB diffusion coefficient [55]. Furthermore, it has been shown that the diffusivity in function of the misorientation of symmetrical tilt GBs displays deep minima for very singular GBs $[15,56]$. Indeed, a special resistance to complete relaxation in $\$ 3$ GBs compared to that in other vicinal and general GBs has been experimentally proved for nickel [57] and copper [58]. In copper complex reactions (combination and annihilation) between extrinsic DSC products occur within the GB yielding further relaxation. However, the relaxation is still incomplete even after a long anneal at $0.75 \mathrm{~T}_{\mathrm{m}}\left(\mathrm{T}_{\mathrm{m}}\right.$ is the melting temperature). It is worth noting that a deformation state, thus a "non-equilibrium" state of the GB may induce an increase in GB diffusivity $[59,60]$, and thus favor decomposition processes.

If the diffusivity in deformed twins must be a little bit higher that in equilibrium twins, it most probably does not reach the diffusivity of general GBs. The structure of twins after deformation is "significant" in so far as it reveals that accommodation processes, and thus 
diffusion, have occurred in GBs.

[Insert figures 13 a-c about here]

These microstructural observations may be related to the macroscopically observed mechanical behaviour of the material [12]. The high level of stress reached during deformation may be attributed to the ultra-fine grain size which limits the interaction between dislocations. Hence, no dislocation locks or entanglements are formed, which considerably reduces the number of impinging points on which sources can be fixed. Intragranular sources are then much less active than intergranular sources, as opposed to the behaviour in coarsegrained material. The absence of interactions between intragranular dislocations may also explain the absence of hardening on the tensile curve after the plateau at constant stress [12]. The work-hardening phenomena responsible for the parabolic hardening in FCC metals are absent. It would appear that the intragranular dislocation density no longer increases with strain. Dislocations emitted from grain boundaries cross the grain interior without interaction and are absorbed sufficiently quickly into opposing grain boundaries. The processes of absorption and accommodation of dislocations in general GBs is more active due to their high diffusivity compared to TBs and consequently require a lower applied stress.

\subsection{Geometric Phase Analysis}

In this work, the geometric phase technique has been applied for the first time to analyse TBs and boundary dislocations. The results reveal the potential of the technique and its complementarity with standard HRTEM image analysis using circuit mapping. Indeed, phase images allow global, direct and rapid visualization of dislocations. The precise in-plane orientation relationship between grains, and dislocation spacing, can be measured, and steps and undulations in the TBs made clearly visible. Moreover, the technique provides information about the dislocation Burgers vectors via the exploitation of the rotation map. Though based on isotropic elasticity theory, results from GPA are systematically consistent 
with Burgers vector determinations from circuit mapping. A rigorous validation of the obtained results requires use of anisotropic elasticity theory as has been performed on olivine [19]. Finally, the absence of a long-range strain field has been established from the calculation of the $\varepsilon_{\mathrm{xx}}$ component of the deformation tensor, in agreement with the quasi-periodic arrangement of boundary dislocations.

\section{Conclusion}

The structure of twin boundaries in UFG copper prepared by powder metallurgy can be summarised as follows:

- TBs are in majority faceted into coherent $\{111\}$ and incoherent $\{112\}$ facets with a Frank dislocation lying at the junction of the facets;

- the incoherent $\{112\}$ facet has a 9R structure;

- the strain fields of extrinsic dislocations are accommodated by incorporation and decomposition mechanisms;

- TBs are enriched in dislocations during deformation, steps are more frequent but smaller, and boundaries adopt a curved morphology.

The fact that intergranular dislocations can rearrange themselves at room temperature means that self diffusion along twin boundaries must be significantly higher than in coarsegrained material. Furthermore, coherent twin boundaries are expected to be particularly low energy and of low diffusivity which means that accommodation mechanisms in general grain boundaries can be expected to be even more favourable. Our observations are consistent with a dislocation-based model of deformation with grain boundaries acting as sources and sinks for dislocations, and in the absence of intragranular dislocation sources and interactions.

Finally, the combination of HRTEM and geometric phase analysis (GPA) has been shown to be extremely valuable for the study of twin boundaries structure in ultra-fine grained copper 
1

2

4

5

6

7

8

9

10

11

12

13

at a nanometer scale, notably for the determination of local stresses and strains and the identification and localisation of intergranular dislocations and steps.

\section{Acknowledgements}

The authors would like to thank Cyril Langlois, Jean-Louis Bonnentien, and Patrick Langlois for providing the UFG Cu specimens, and Cécilie Duhamel and Sandrine Guerin for carrying out the compression tests. Professor Louisette Priester is gratefully acknowledged for valuable discussions and her critical reading of the manuscript. 


\section{References}

[1] H. Gleiter, Prog. Mater. Sci. 33223 (1991).

[2] M.F. Ashby, R.A. Verrall, Acta Metall. 21149 (1973).

[3] R.Z. Valiev, T.G. Langdon. Acta Metall. 41949 (1993).

[4] M.G. Zelin, A.K. Mukherjee. Phil. Mag. 681183 (1993).

[5] M.J. Hÿtch, E. Snoeck and R. Kilaas, Ultramicroscopy 74131 (1998).

[6] Z. Horita, D.J. Smith, M. Nemoto, et al., J. Mater. Res. 13446 (1998).

[7] J.H. Huang, Y.T. Zhu and H. Jiang, Acta Mater. 491497 (2001).

[8] J.H. Huang, X.Z. Liao, Y.T Zhu, et al., Phil. Mag. 831407 (2003).

[9] L. Lu, Y. Shen, X. Chen, et al., Science 304422 (2004).

[10] Y.F. Shen, L. Lu, Q.H. Lu, et al., Scripta mater. 52989 (2005).

[11] L. Lu, R. Schwaiger, Z.W. Shan, et al., Acta mater. 532169 (2005).

[12] Y. Champion, C. Langlois, S. Guérin, et al., Science 300310 (2003).

[13] C. Langlois, M.J. Hÿtch, P. Langlois, et al., Metal. Trans. 36A 3451 (2005).

[14] L. Priester, Interface science 4205 (1997).

[15] R.W. Balluffi, "Diffusion in crystalline solids",Ed. G.E. Musch and A.S. Nowick, Academic press, New york (1984).

[16] L. Priester, S. Lartigue, J. of Europ. Ceram. Soc. 847 (1991).

[17] A.H. King, D.A. Smith, Acta Cryst. A 36335 (1980).

[18] M.J. Hÿtch, J.L. Putaux and J.M. Pénisson, Nature 423270 (2003).

[19] C.L. Johnson, M.J. Hÿtch and P.R Buseck, PNAS 10117936 (2004).

[20] Y. Champion, J. Bigot, Mater. Sci. Eng. 101097 (1998).

[21] F. Hüe, C.L. Johnson, S. Lartigue Korinek, et al., J. of Elect. Microsc. 54(3) 181 (2005)

[22] W.T. Read, W. Shockley, Phys. Rev. 78275 (1950).

[23] J.M. Pénisson, U. Dahmen and J. Mills, Phil. Mag. Let. 64277 (1991). 
[24] W. Krakow, D.A. Smith, Ultramicroscopy 2247 (1987).

[25] H. Ichinose, Y. Ishida, N. Baba, et al., Phil. Mag. A 5251 (1985).

[26] U. Wolf, P. Gumbsh, H. Ichinose, et al., J. Phys. Paris 51 C1-359 (1990).

[27] F. Ernst, M.W. Finnis, D. Hofman, et al., Phys. Rev. Lett. 69(4) 620 (1992).

[28] D. Hofmann, M.W. Finnis, Acta metall. Mater. 42(10) 3555 (1994)

[29] U. Wolf, F. Ernst, T. Muschik, et al., Phil. Mag. A 66991 (1992).

[30] T. Muschik, W. Laub, U. Wolf, et al., Acta metall. Mater. 41(7) 2163 (1993).

[31] D. Hofmann, F. Ernst, Ultramicroscopy 53205 (1994).

[32] G.H. Campbell, D.K. Chan, D.L. Medlin, et al., Scripta mater. 35(7) 837 (1996).

[33] B. Weiler, W. Sigle and A. Seeger, Phys. Stat. Sol. A 150221 (1995).

[34] B.J. Pestman, J.T. De Hosson, V. Vitek, et al., Phil. Mag. 64951 (1991).

[35] J.L. Putaux, PhD thesis, university of Grenoble, France, 1991.

[36] J.Y. Huang, Y.K. Wu and H. Q. Ye, Acta Mater. 44(3) 1211 (1996).

[37] M.S. Szczerba, T.Bajor and T. Tokarski, Phil. Mag. 84481 (2004).

[38] R.Z. Valiev, I.M. Razumovski and V.I. Sergeev, Phys. Stat. Sol. (a) 139321 (1993)

[39] O. Dominguez, Y. Champion and J. Bigot, Scripta Mater. 29A 2941 (1998).

[40] L. Priester, Mat.Sci. Eng. A 309-310 430 (2001).

[41] Z. Shen, R.H. Waggoner and A.T. Clark, Scripta Metall., 20921 (1986).

[42] T.C. Lee, I.M. Robertson and H.K. Birnbaum, Scripta Metall., 23799 (1989).

[43] T.C. Lee, I.M. Robertson and H.K. Birnbaum, Phil. Mag. A 62131 (1990).

[44] M. Polcarova, J. Gemperlova, J. Bradler, et al., Phil. Mag. A 78105 (1998).

[45] A. Gemperle, N. Zarubova and J. Gemperlova, J. Mat. Sci. 403247 (2005)

[46] C.T. Forwood, P. Humble, Phil. Mag. 311025 (1975).

[47] M. Elkabaji, J. Thibault-Desseaux. Phil. Mag. 58325 (1988).

[48] A.H. King, F.C. Chen, Mater. Sci. Eng. 66227 (1984). 
[49] S. Poulat, B. Decamps and L. Priester, Phil. Mag. A 771381 (1998)

[50] J.P. Couzinié, B. Decamps and L. Priester, Phil. Mag. 83721 (2003).

[51] J.P. Couzinié, B. Decamps and L. Priester, Int. J. Plasticity 21759 (2005).

[52] J. Thibault-Desseaux, J.L. Putaux, A. Bourret, et al., J. Phys. 502525 (1989)

[53] D.P. Fields, B.W. True, T.M. Lillo, et al., Mater. Sci. Eng. A 372173 (2004).

[54] W.A. Swiatnicki, M.W. Grabski, Acta Metall. 34817 (1986).

[55] A. Nazarov, Interface Science 871 (2000).

[56] I. Herbeuval, M. Bicondi and C. Goux, Mém. Sci. Rev. Met. 7039 (1973).

[57] S. Poulat, B. Decamps and L. Priester, Phil. Mag. A 792655 (1999).

[58] L. Priester, J.P. Couzinie, B. Decamps, et al., in "Evolution of deformation in 3D", Ed.

C. Gundlach et al., Ris National laboratory, Roskilde, Denmark, p.79 (2004).

[59] V.N. Perevezentsev, V.V. Rybin and V.N. Chuvil'deev, Acta Metall. 40887 (1992).

[60] J.S. Vetrano, E.P. Simonen and S.M. Bruemmer, Acta Mater. 474125 (1999). 


\section{Figure and Table captions}

Table 1: Statistical analysis results with $d_{m}$ and $h_{m}$ the average of dislocation spacing and step height respectively, $\sigma$ indicates the corresponding standard deviation.

Figure 1. (a) TEM micrograph of the general microstructure in the as-processed specimen showing ultra-fine grains and parallel twin bands (b); (c) Twins boundaries are in majority faceted into coherent $\{111\}$ and incoherent $\{112\}$ facets. The latter are faulted and slightly inclined (moiré fringes) (d).

Figure 2. Geometric phase analysis of a faceted TB: (a) HRTEM image of the TB. Inset is the Fourier transform of the image; (b) phase image calculated from the set of $(11 \overline{1})_{1}=(111)_{2}$ lattice fringes showing an arrangement dislocations along the boundary. Dislocations cores are denoted by the $\perp$ symbols.

Figure 3. Experimental ((a) and (b)) and simulated (isotropic elastic theory) ((c) and (d)) maps of a boundary segment containing Frank dislocations. A good agreement is observed.

Figure 4. HRTEM image obtained along [1ํㅣㄹ zone axis on a faceted TB. Careful inspection of the image reveals the presence of a dislocation located at the $\{111\} /\{112\}$ junction. Using circuit mapping technique (King and Smith method), it has been identified as a Frank

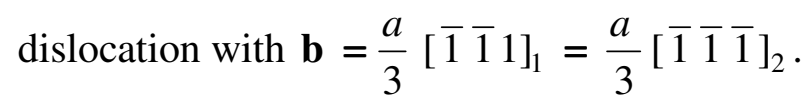

Figure 5. Enlargement of a coherent $\{111\}$ facet showing a local atomic structure change near the $\{111\} /\{112\}$ junctions (see arrow) and the presence of faulted regions (outlined zone at the bottom of the image). The total Burgers vector around the defect is equal to 
$\mathbf{b}^{*}=\frac{a}{6}[\overline{1} \overline{1} \overline{2}]_{1}=\frac{a}{6}[11 \overline{2}]_{2}$. This is attributed to the dissociation of a Shockley glissile dislocation into two products resulting in a stacking fault delimited by two partials of the type $\frac{a}{12}[\overline{1} \overline{1} \overline{2}]_{1}=\frac{a}{12}[11 \overline{2}]_{2}$. Shockley glissile dislocations with Burgers vector $\mathbf{b}^{* *}=\frac{a}{6}<112>$ are also observed.

Figure 6. (a) Enlargement of an incoherent $\{112\}$ facet. Analysis of its atomic structure revealed a $9 \mathrm{R}$ structure $(\mathrm{b})$.

Figure 7. HRTEM images showing a $60^{\circ}$ lattice dislocation $\left(\mathbf{b}=\frac{a}{2}[\overline{1} 01]_{1}\right.$ or $\left.\frac{a}{2}[0 \overline{1} 1]_{1}\right)$ close to the TB;

Figure 8. (a) Frank dislocation dissociating out of the boundary. The dissociation products are identified, using phase image of $(11 \overline{1})_{1} /(111)_{2}$ planes (b) and the corresponding rotation map (c), as lattice Shockley partial $\left(\mathbf{b}=\frac{a}{6}[\overline{1} \overline{1} 2]_{1}\right)$ and boundary sessile (stair-rod)

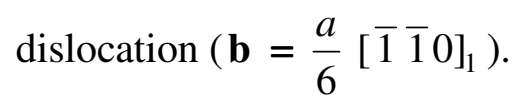

Figure 9. HRTEM image of a TB step associated to a sessile perfect lattice dislocation, a Lomer dislocation.

Figure 10. TEM images obtained on the deformed material showing: (a) twin boundaries enriched in dislocations; (b) several deformation induced micro-twins.

Figure 11. HRTEM image of a step in the deformed material. The associated dislocation is identified as of Frank type. 
Figure 13. (a) Bright field TEM image showing lattice dislocations $\left(\mathbf{b}=\frac{a}{2}[\overline{1} 01]\right)$ "attached" to twin steps (as-processed specimen); (b) dark field image of a grain in the deformed specimen showing curved dislocations emitted from the triple junctions in the left twin boundary and a periodic dislocations array along the right twin boundary; (c) $(0 \overline{2} 0)$ dark field image of the same grain showing a periodic dislocations array along a general GB in the top of the grain. 


\begin{tabular}{lll}
\hline Material & $d_{m}(\mathrm{~nm})$ & $h_{m}(\mathrm{~nm})$ \\
\hline As-processed & $5.5\left(\sigma_{=} 0.6\right)$ & $1.45\left(\sigma_{=} 0.25\right)$ \\
Deformed & $2.3\left(\sigma_{=0.1)}\right.$ & $0.4\left(\sigma_{=} 0.05\right)$ \\
\hline
\end{tabular}




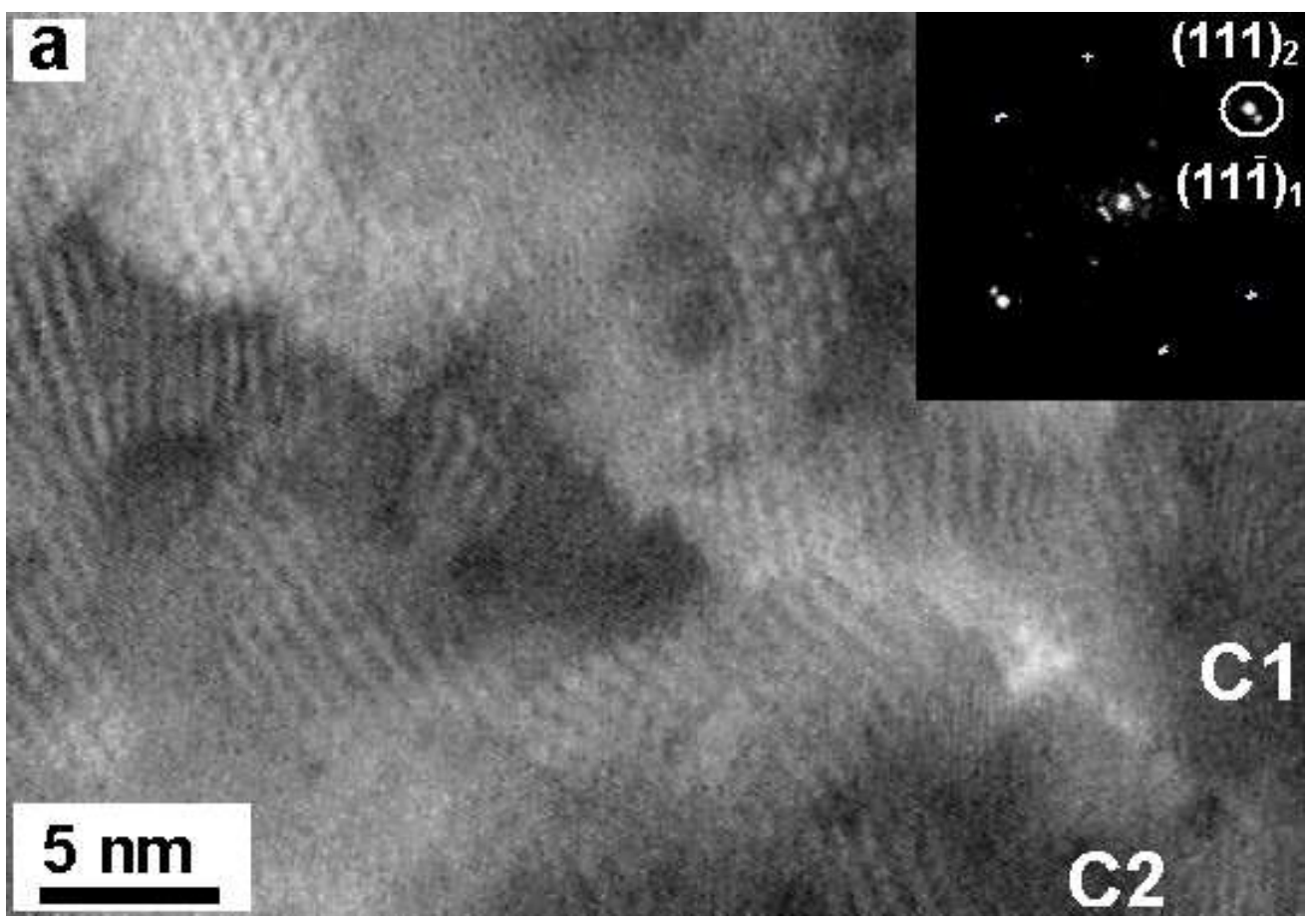

$114 \times 79 \mathrm{~mm}(120 \times 120 \mathrm{DPI})$ 
Philosophical Magazine \& Philosophical Magazine Letters

Page 32 of 49

1
2
3
4
5
6
7
8
9
10
11
12
13
14
15
16
17
18
19
20
21
22
23
24
25
26
27
28
29
30
31
32
33
34
35
36
37
38
39
40
41
42
43
44
45
46
47
48
49
50
51
52
53
54
55
56
58
59
60

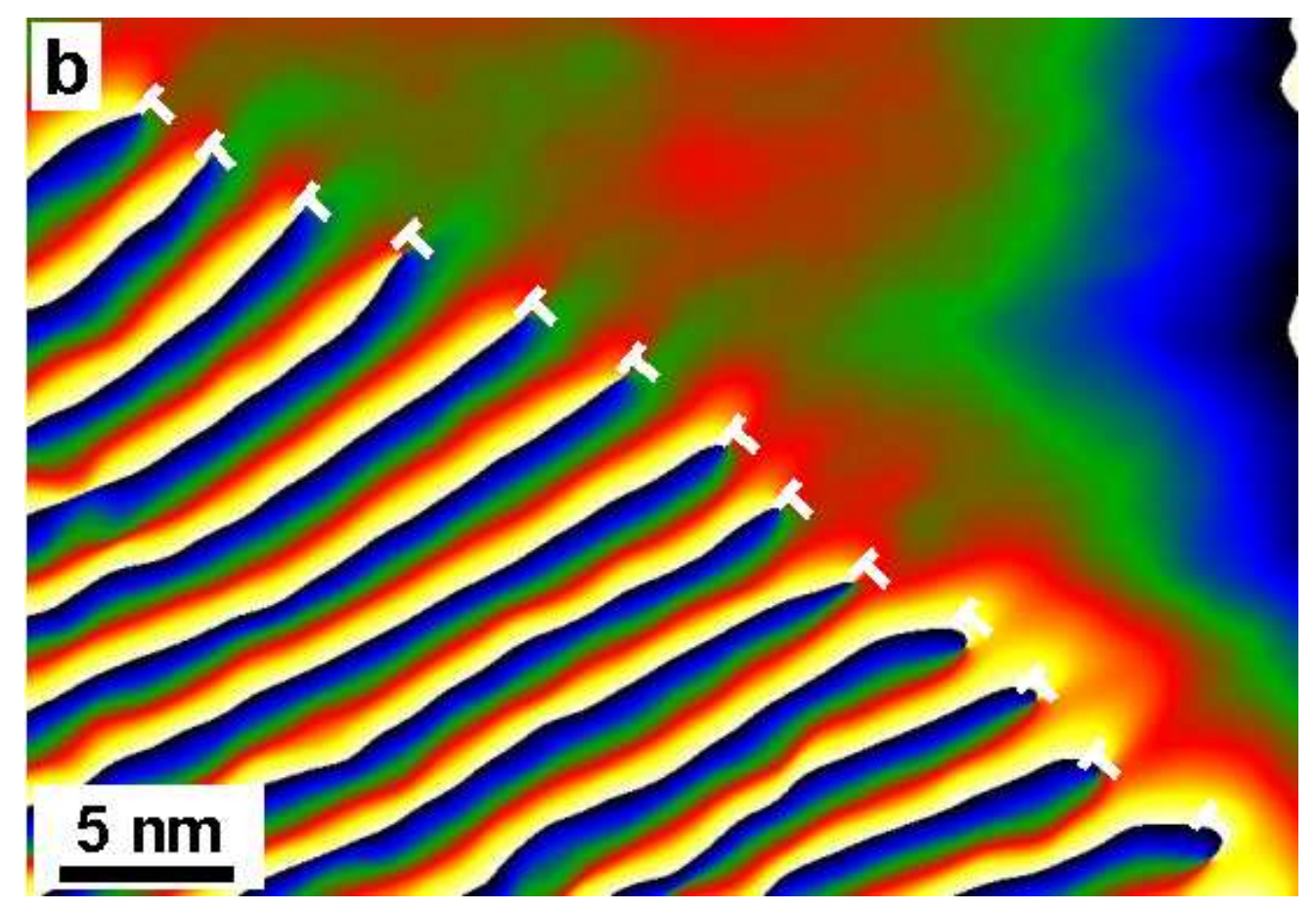

$115 \times 80 \mathrm{~mm}(120 \times 120 \mathrm{DPI})$

http://mc.manuscriptcentral.com/pm-pml 

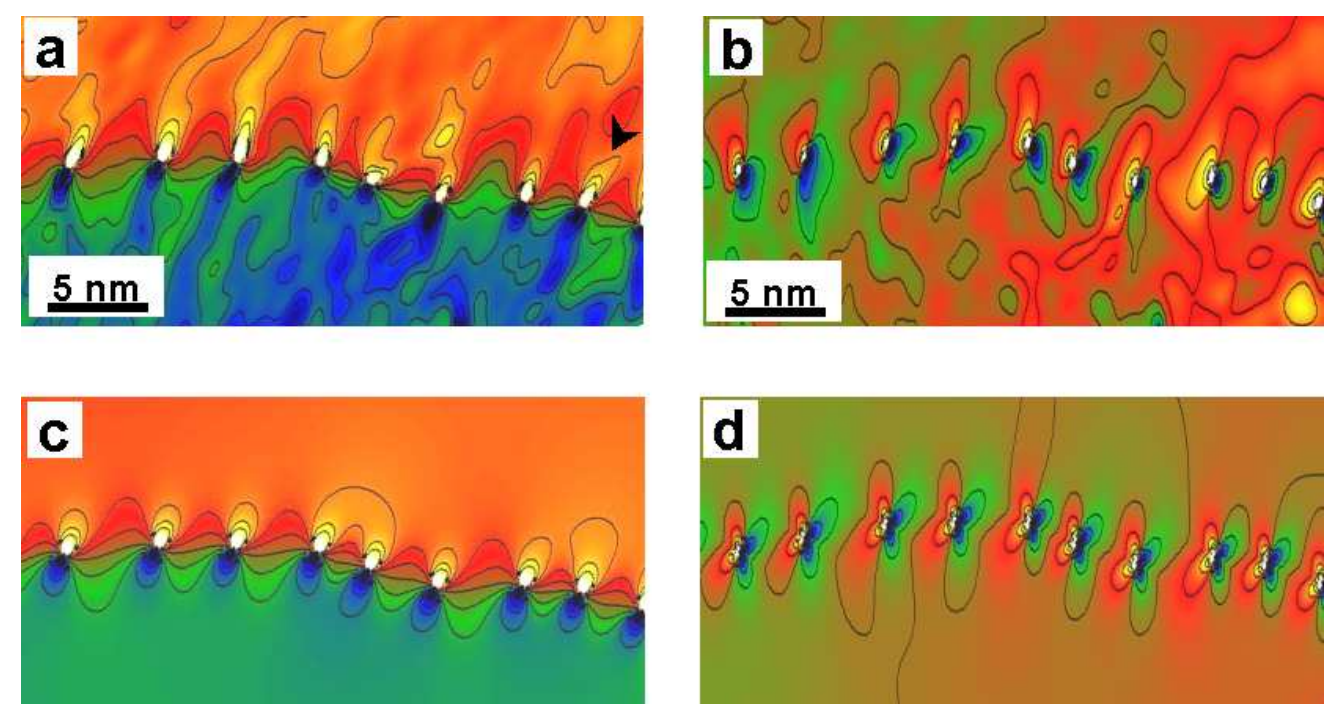

219x116mm (96 x 96 DPI) 


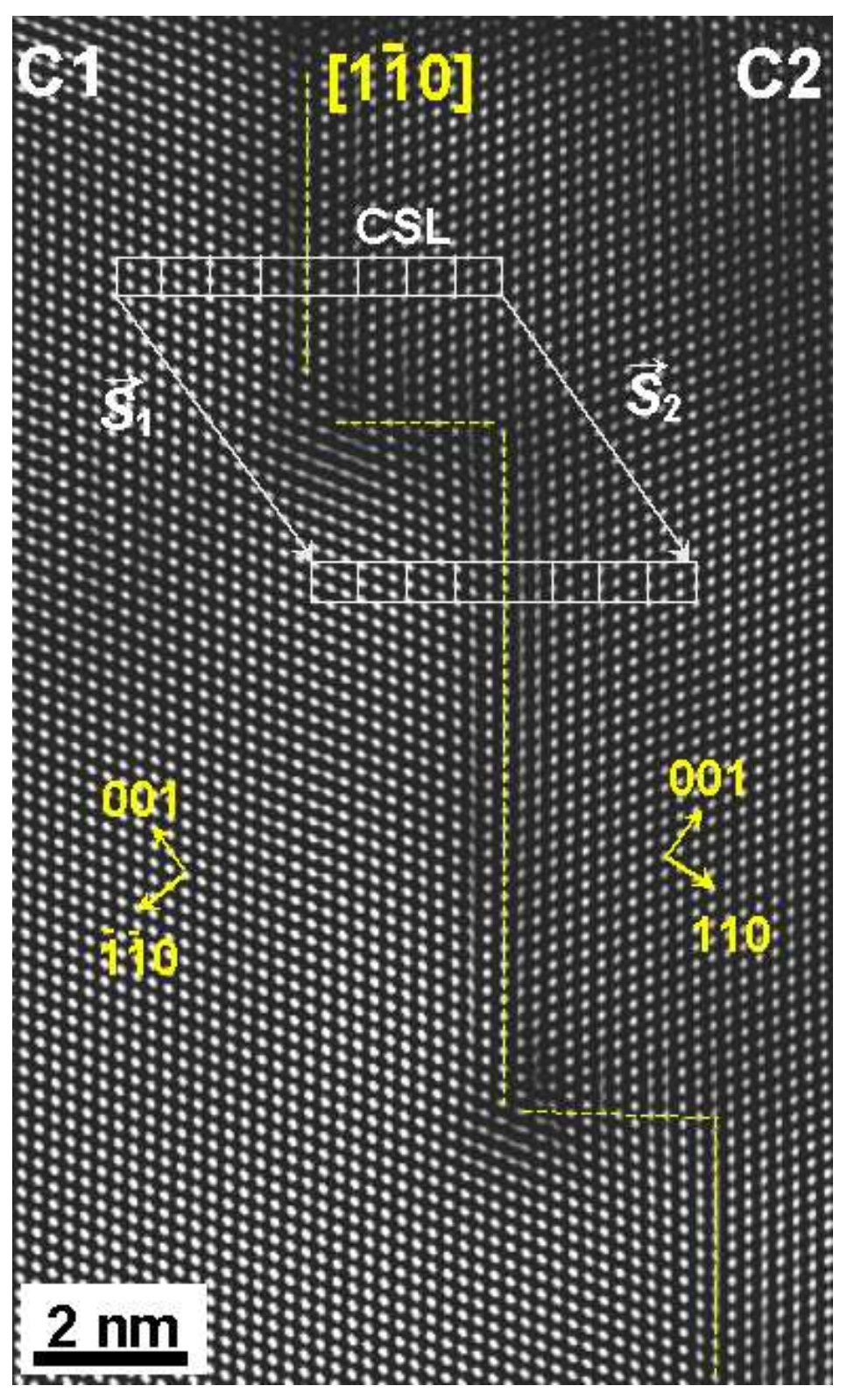

$82 \times 137 \mathrm{~mm}(120 \times 120 \mathrm{DPI})$ 


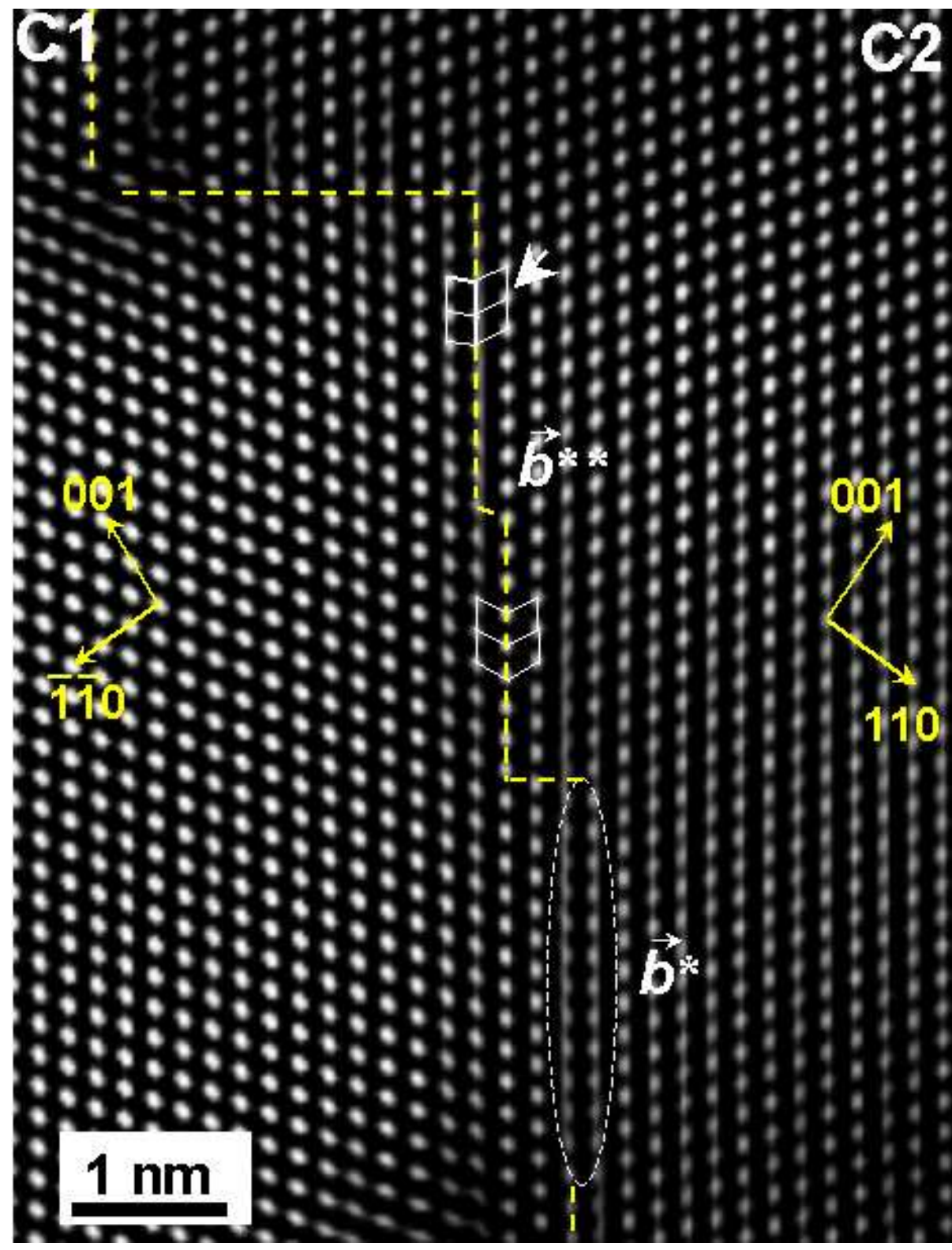

$98 \times 129 \mathrm{~mm}(120 \times 120$ DPI $)$ 


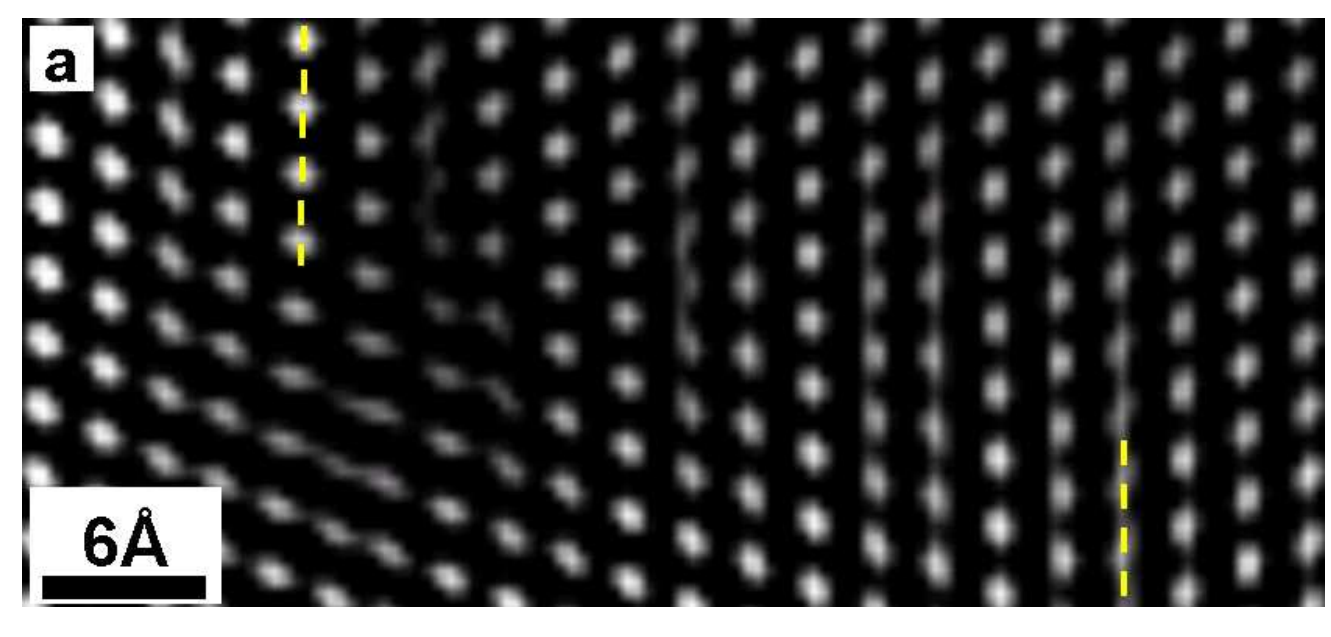

$176 \times 80 \mathrm{~mm}(120 \times 120 \mathrm{DPI})$

1
2
3
4
5
6
7
8
9
10
11
12
13
14
15
16
17
18
19
20
21
22
23
24
25
26
27
28
29
30
31
32
33
34
35
36
37
38
39
40
41
42
43
44
45
46
47
48
49
50
51
52
53
54
55
56
57
58
50




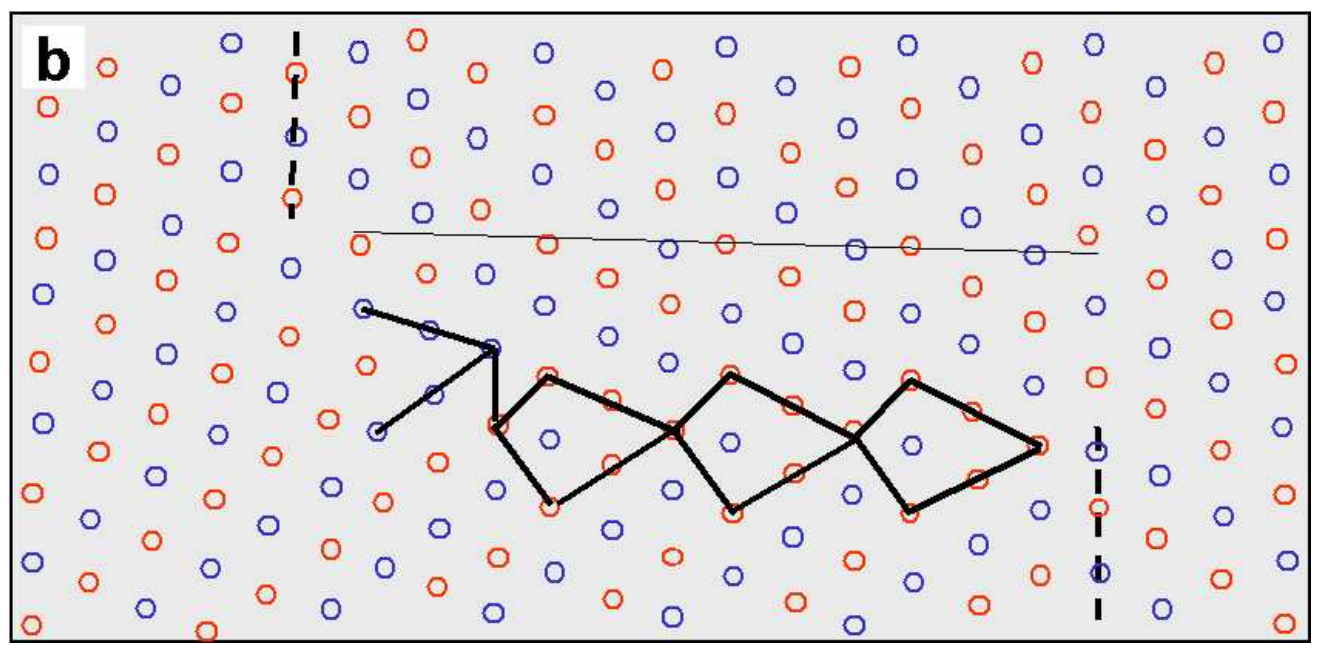

$178 \times 87 \mathrm{~mm}(120 \times 120$ DPI $)$

1
2
3
4
5
6
7
8
9
10
11
12
13
14
15
16
17
18
19
20
21
22
23
24
25
26
27
28
29
30
31
32
33
34
35
36
37
38
39
40
41
42
43
44
45
46
47
48
49
50
51
52
53
54
55
56
57
58
59
60




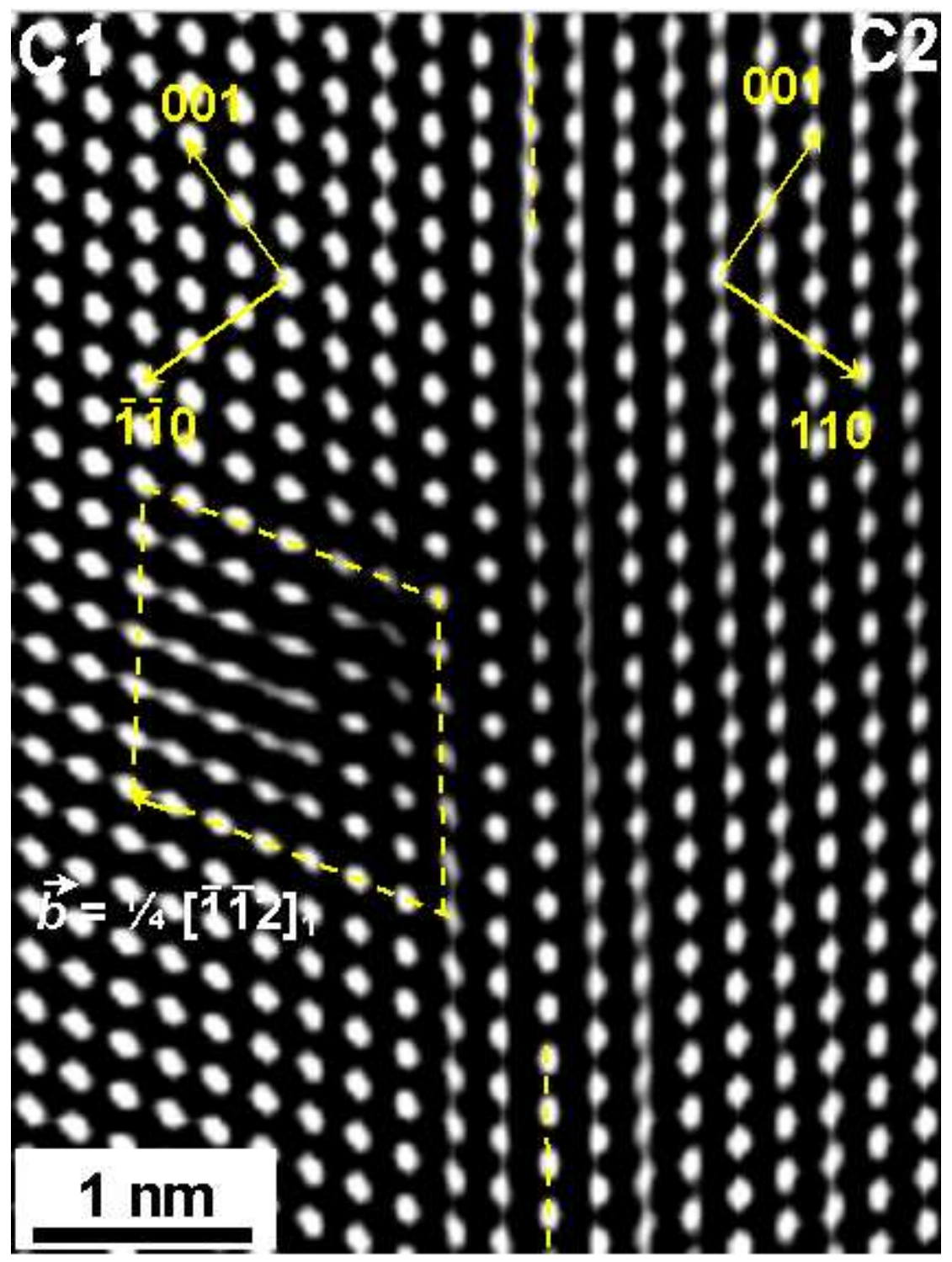

$89 \times 120 \mathrm{~mm}(120 \times 120$ DPI $)$ 


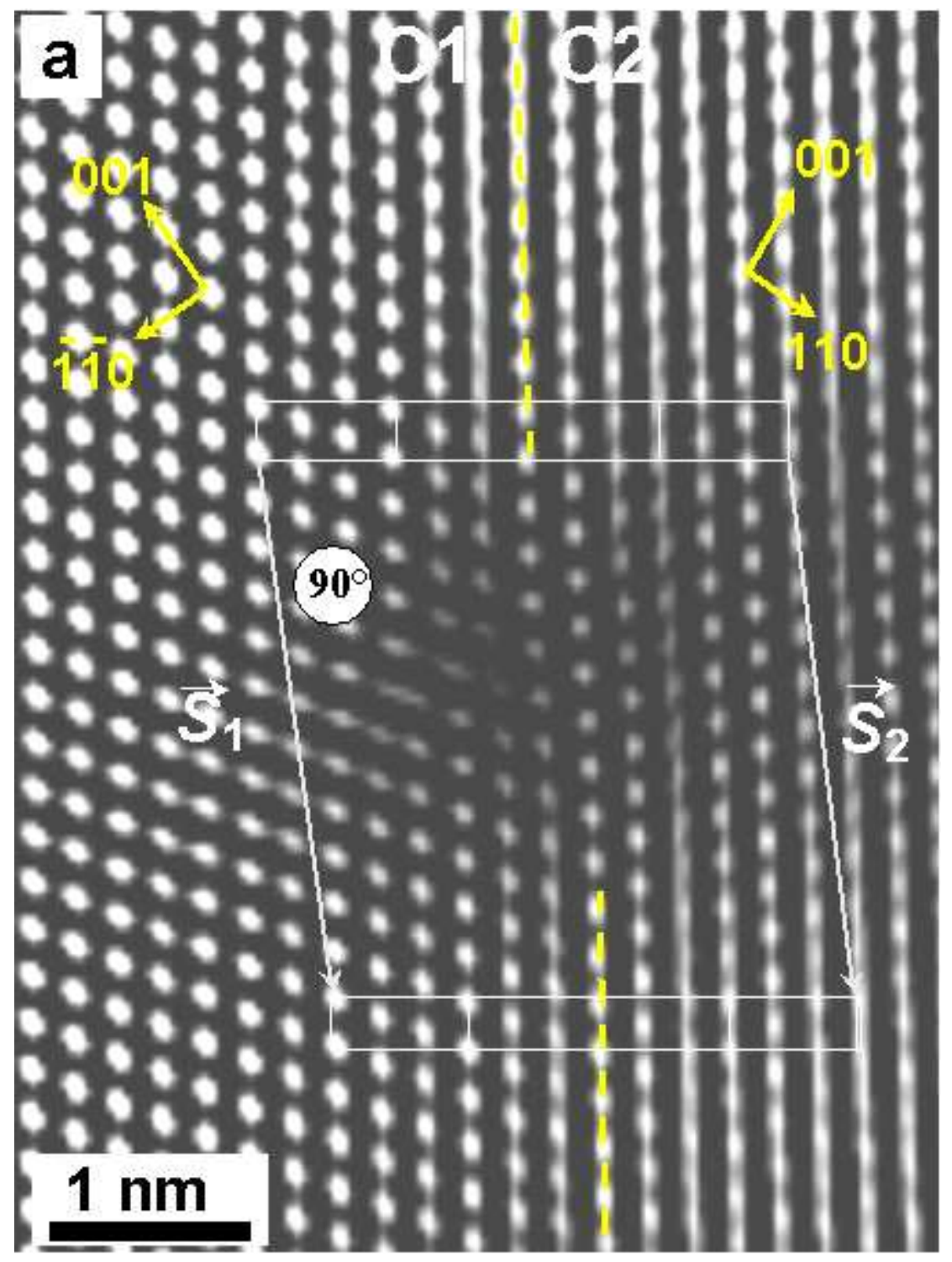

$111 \times 150 \mathrm{~mm}(96 \times 96 \mathrm{DPI})$ 


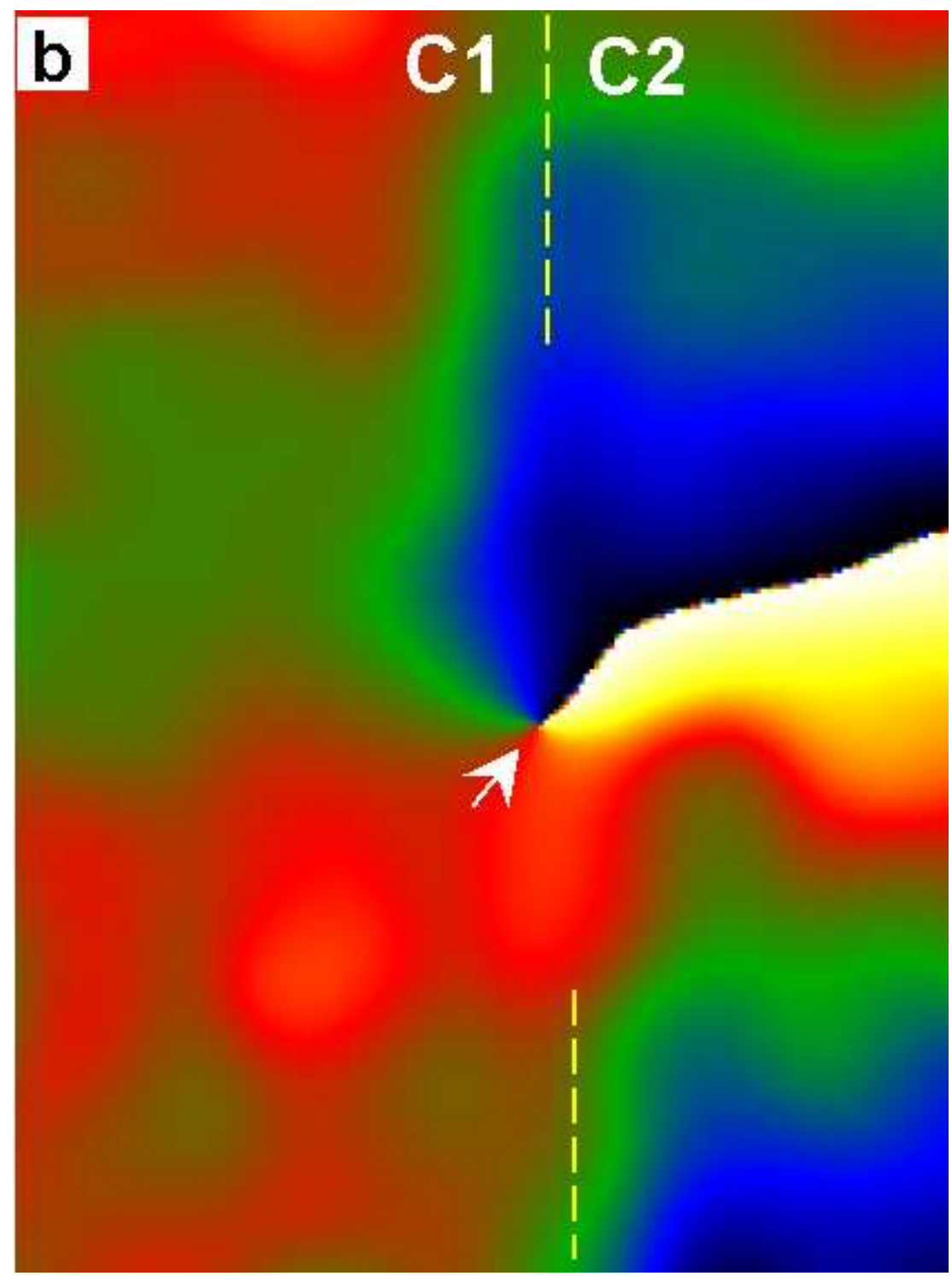

$111 \times 150 \mathrm{~mm}(96 \times 96 \mathrm{DPI})$ 


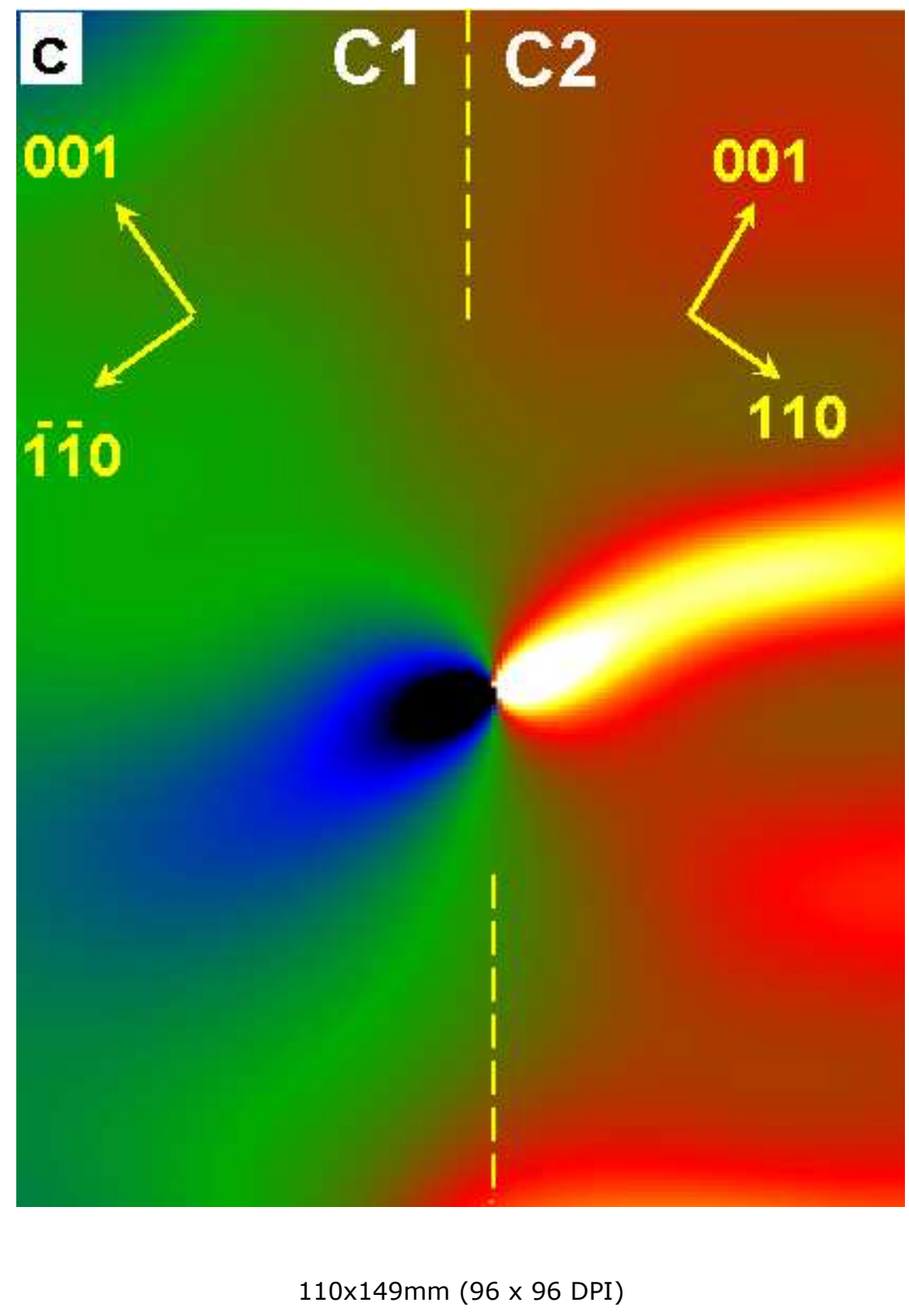

http://mc.manuscriptcentral.com/pm-pml 


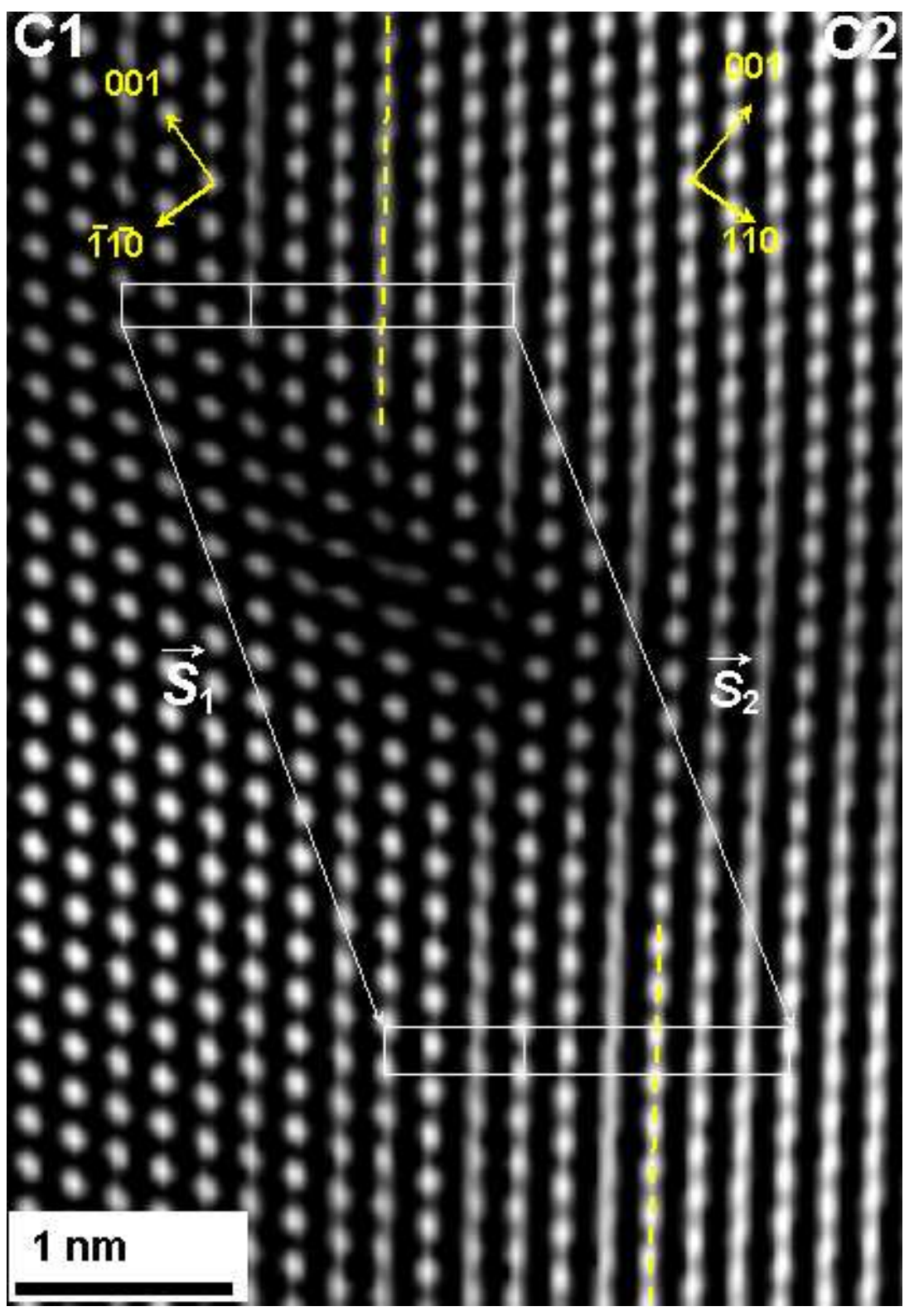

$110 \times 159 \mathrm{~mm}(96 \times 96$ DPI) 


1
2
3
4
5
6
7
8
9
10
11
12
13
14
15
16
17
18
19
20
21
22
23
24
25
26
27
28
29
30
31
32
33
34
35
36
37
38
39
40
41
42
43
44
45
46
47
48
49
50
51
52
53
54
55
56
57
59
60

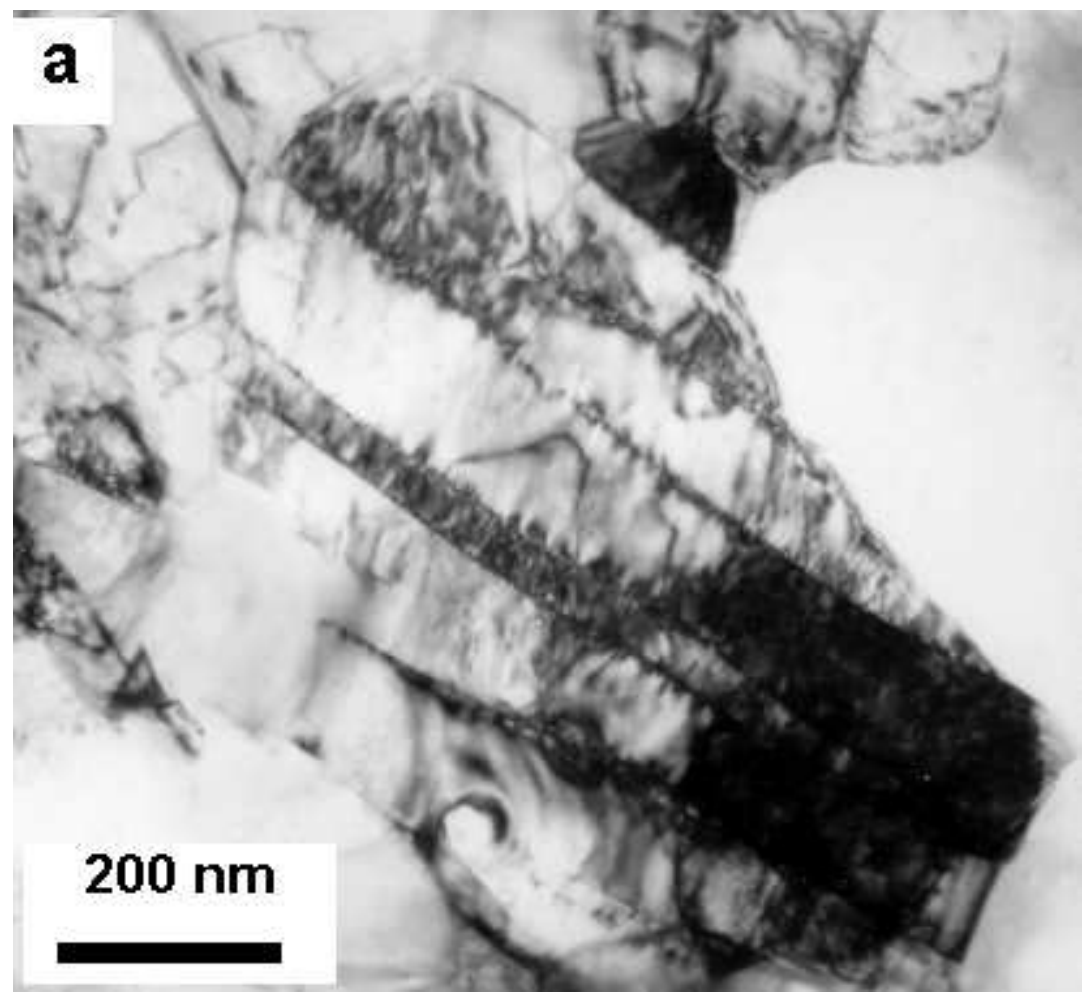

$108 \times 99 \mathrm{~mm}(96 \times 96 \mathrm{DPI})$ 36 37 38 39 40 41 


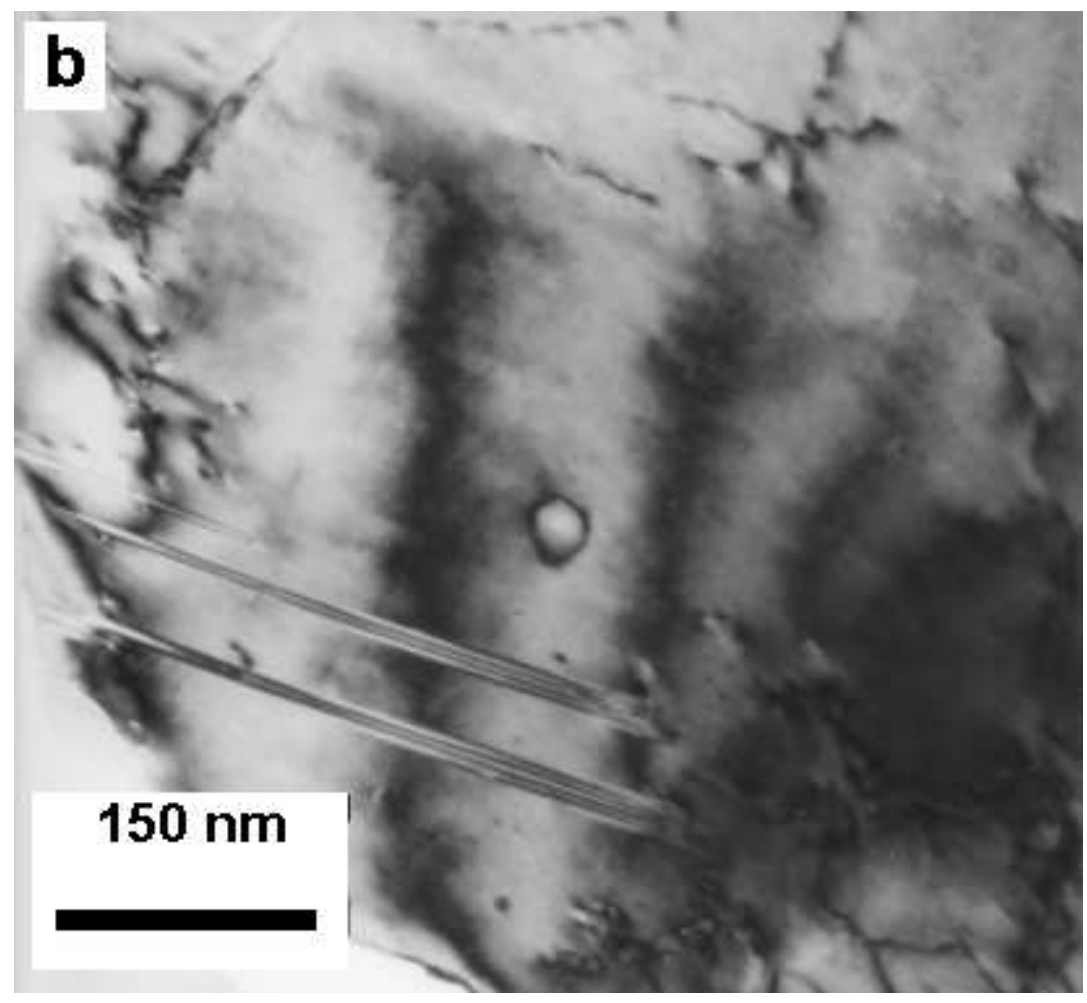

$108 \times 99 \mathrm{~mm}(96 \times 96 \mathrm{DPI})$ 


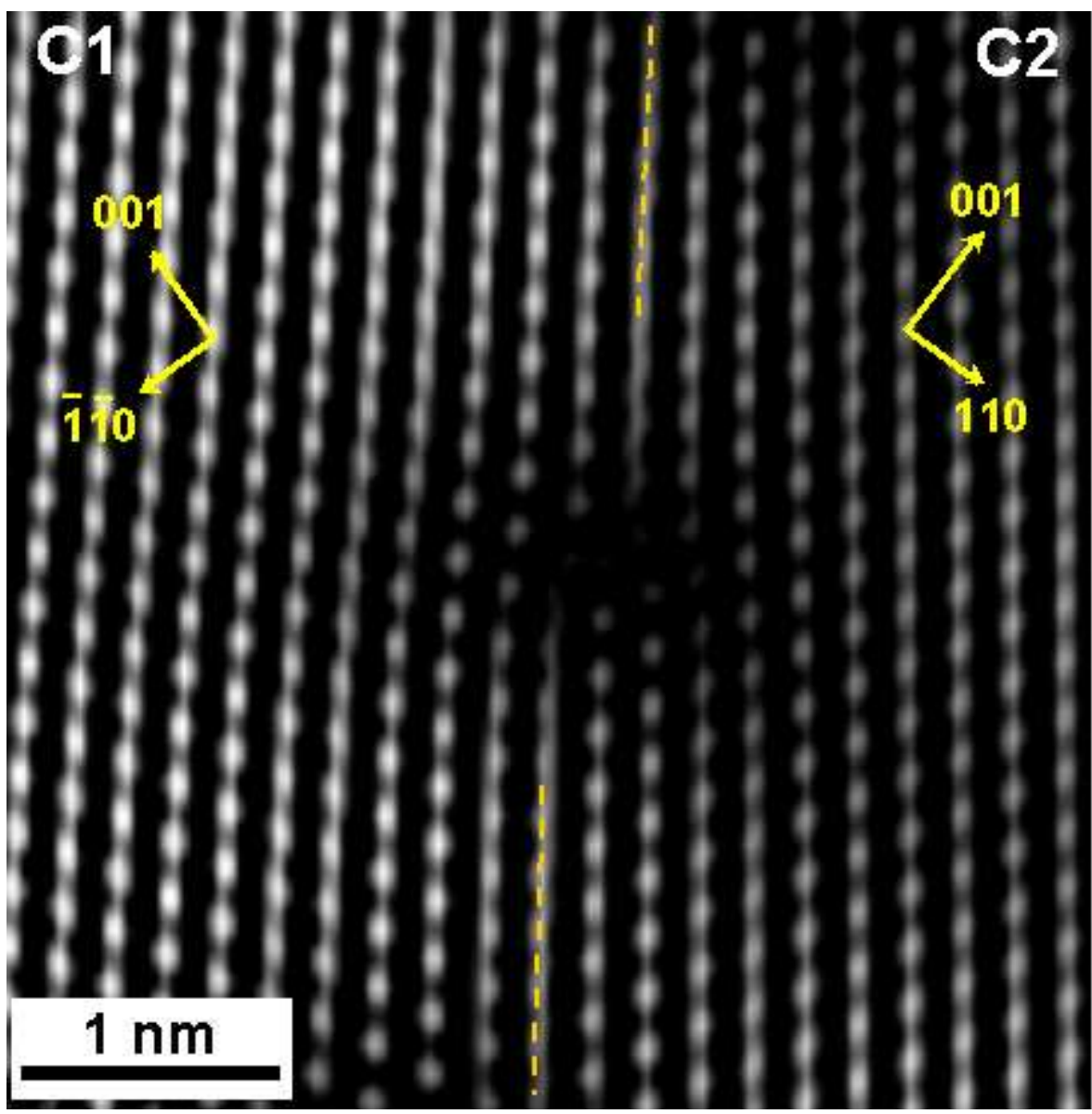

$118 \times 120 \mathrm{~mm}(96 \times 96 \mathrm{DPI})$ 

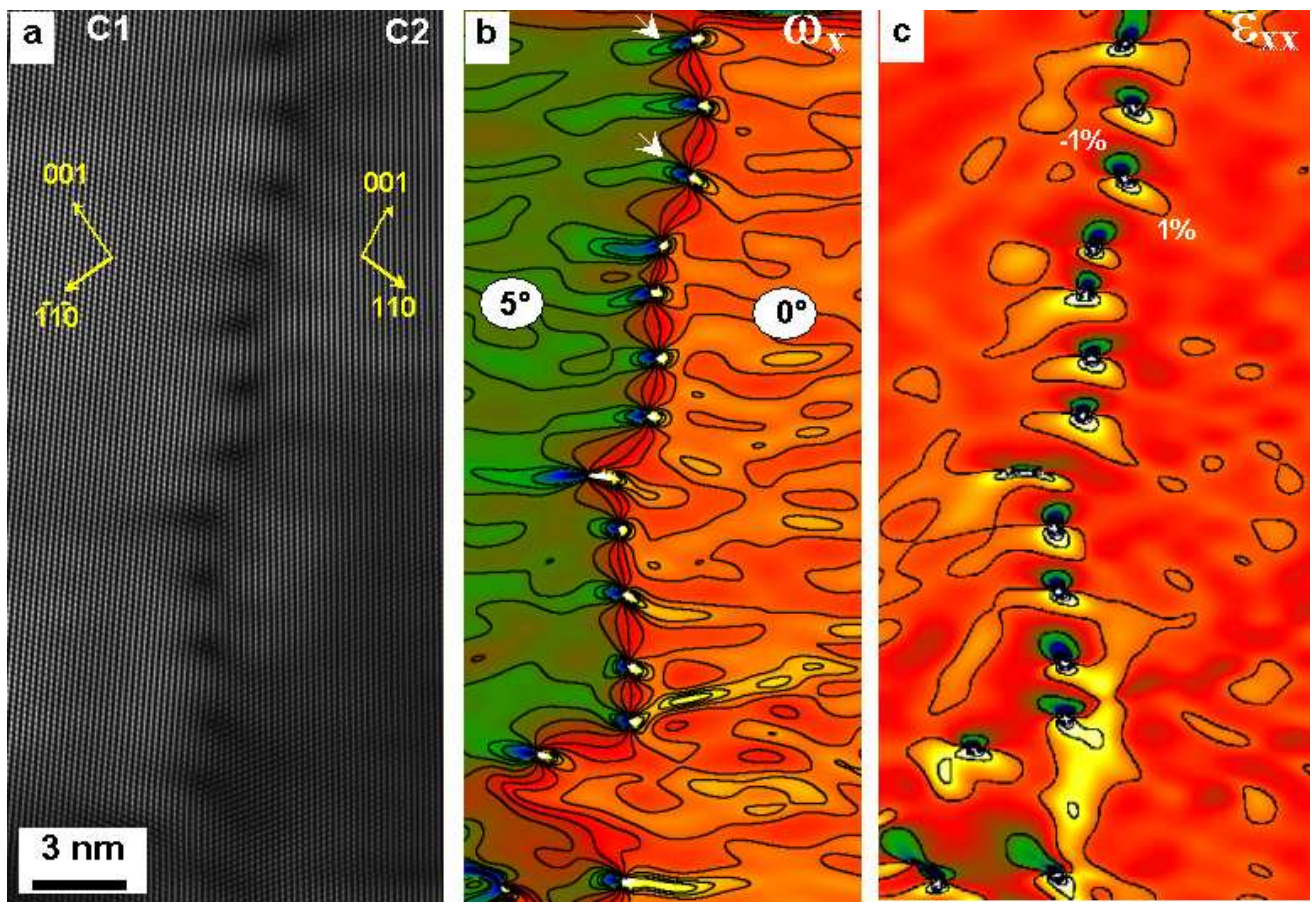

$204 \times 139 m m(96 \times 96$ DPI) 


1
2
3
4
5
6
7
8
9
10
11
12
13
14
15
16
17
18
19
20
21
22
23
24
25
26
27
28
29
30
31
32
33
34
35
36
37
38
39
40
41
42
43
44
45
46
47
48
49
50
51
52
53
54
55
56
57
59
60

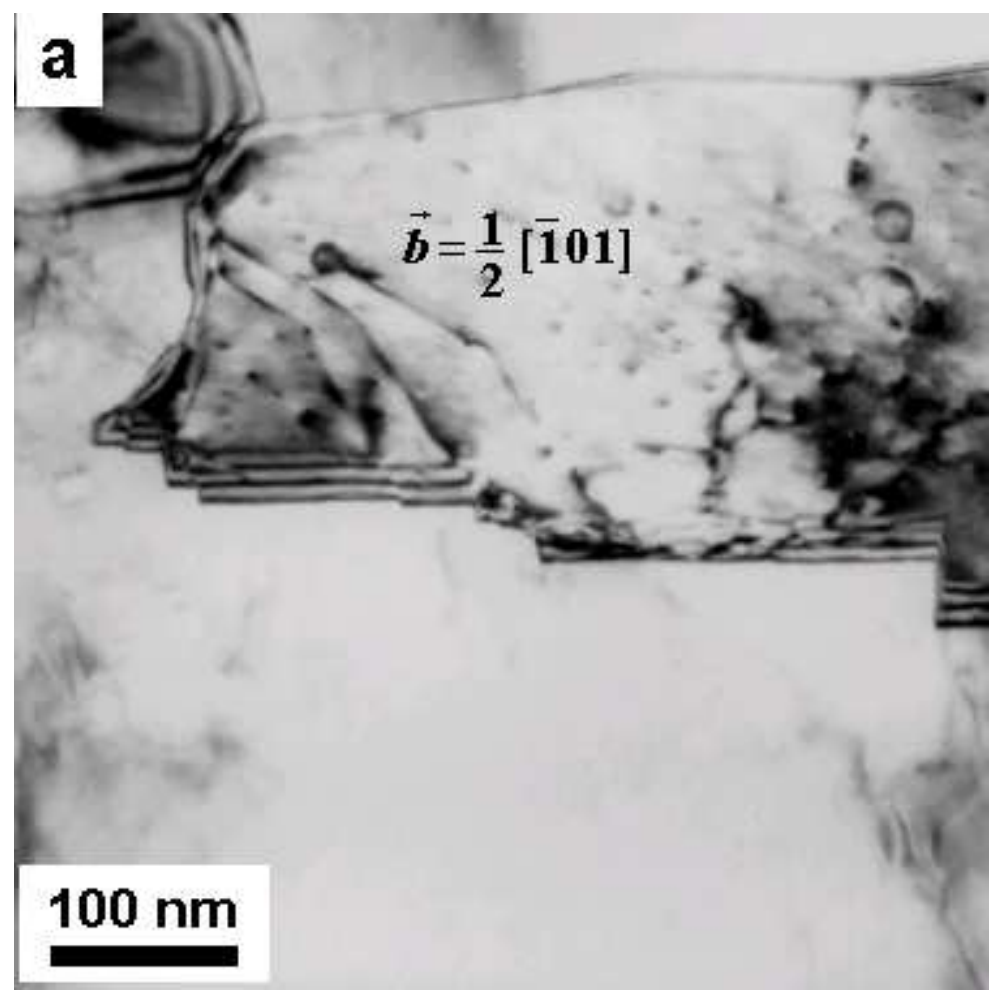

$98 \times 99 \mathrm{~mm}(96 \times 96 \mathrm{DPI})$ 


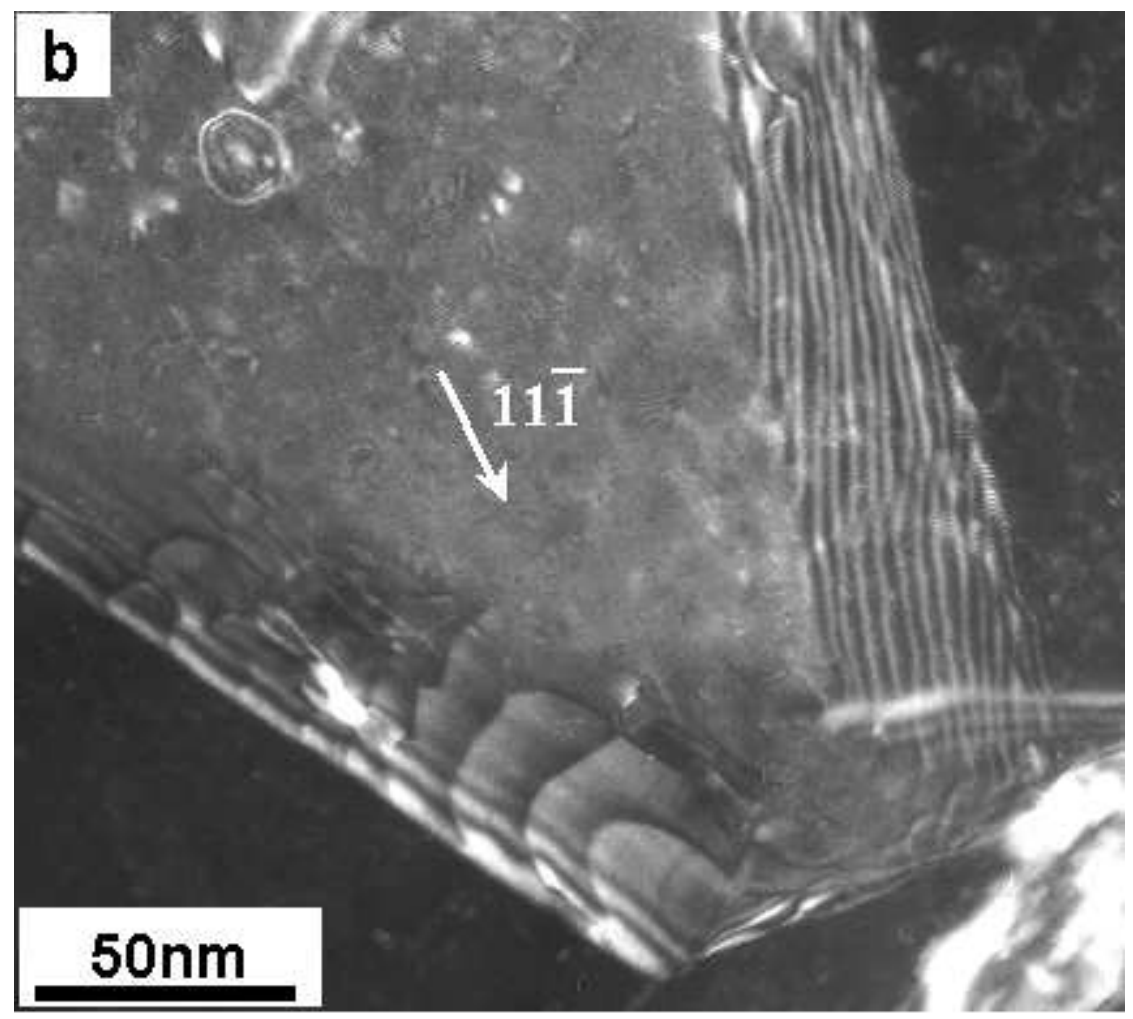

$112 \times 102 \mathrm{~mm}(96 \times 96 \mathrm{DPI})$ 


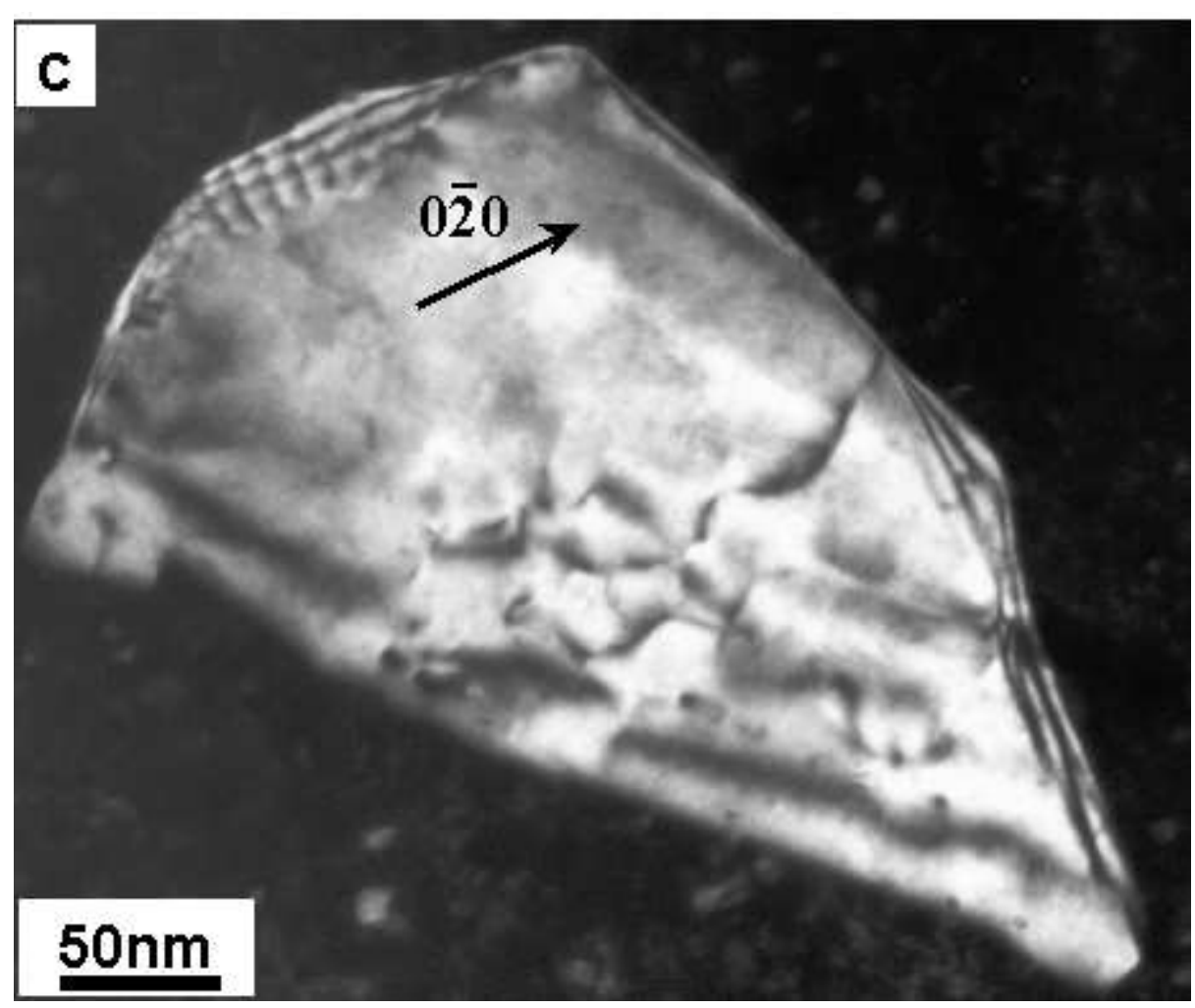

$121 \times 102 \mathrm{~mm}(96 \times 96$ DPI) 